\title{
CAMA
}

Centre for Applied Macroeconomic Analysis

\section{Effects of US Monetary Policy Shocks During Financial Crises - A Threshold Vector Autoregression Approach}

\section{CAMA Working Paper 64/2013 September 2013}

Jasmine Zheng

Centre for Applied Macroeconomic Analysis (CAMA), ANU

\section{Abstract}

This paper analyzes the impact and effectiveness of conventional monetary policy during periods of low and high financial stress in the US economy. Using data from 1973Q1 to 2008Q4, the analysis is conducted by estimating a Threshold Vector Autoregression (TVAR) model to capture switching between the low and high financial stress regimes implied by the theoretical literature. The empirical findings support regime-dependent effects of conventional US monetary policy. In particular, the output response to monetary policy shocks is larger during periods of high financial stress than in periods of low financial stress. The existence of a cost channel effect during periods of high financial stress imply a worsening of the short run output-inflation trade off during financial crises. When the sample period is extended to 2012Q4, there is evidence that expansionary monetary policy continues to be effective during periods of high financial stress when the prevailing interest rate is at the zero lower bound. By keeping interest rates and credit spreads low, expansionary monetary policy helps shift the US economy from high to low financial stress regimes. Large expansionary monetary policy shocks also increase the likelihood of moving the economy out of a high financial stress regime. 


\section{Keywords}

Monetary policy, uncertainty, threshold vector autoregression models

\section{JEL Classification}

F44, E44, E52

\section{Address for correspondence:}

(E) cama.admin@anu.edu.au

The Centre for Applied Macroeconomic Analysis in the Crawford School of Public Policy has been established to build strong links between professional macroeconomists. It provides a forum for quality macroeconomic research and discussion of policy issues between academia, government and the private sector.

The Crawford School of Public Policy is the Australian National University's public policy school, serving and influencing Australia, Asia and the Pacific through advanced policy research, graduate and executive education, and policy impact. 


\title{
Effects of US Monetary Policy Shocks During Financial Crises - A Threshold Vector Autoregression Approach ${ }^{* \dagger}$
}

\author{
Jasmine Zheng \\ Centre for Applied Macroeconomic Analysis (CAMA) \\ The Australian National University
}

September 2013

\begin{abstract}
This paper analyzes the impact and effectiveness of conventional monetary policy during periods of low and high financial stress in the US economy. Using data from 1973Q1 to 2008Q4, the analysis is conducted by estimating a Threshold Vector Autoregression (TVAR) model to capture switching between the low and high financial stress regimes implied by the theoretical literature. The empirical findings support regime-dependent effects of conventional US monetary policy. In particular, the output response to monetary policy shocks is larger during periods of high financial stress than in periods of low financial stress. The existence of a cost channel effect during periods of high financial stress imply a worsening of the short run output-inflation trade off during financial crises. When the sample period is extended to 2012Q4, there is evidence that expansionary monetary policy continues to be effective during periods of high financial stress when the prevailing interest rate is at the zero lower bound. By keeping interest rates and credit spreads low, expansionary monetary policy helps shift the US economy from high to low financial stress regimes. Large expansionary monetary policy shocks also increase the likelihood of moving the economy out of a high financial stress regime.
\end{abstract}

Keywords: Monetary policy, uncertainty, threshold vector autoregression models

JEL Classification: F44, E44, E52

\footnotetext{
*Corresponding author: jasmine.zheng@anu.edu.au.

†I am grateful for comments from Renée Fry-Mckibbin, Warwick Mckibbin, Ippei Fujiwara, and seminar participants at The Australian National University.
} 


\section{Introduction}

In the last 40 years, the world economy has experienced several financial crises and periods of high financial stress. The major periods of high financial stress include: the 1977 international banking crisis; the 1984 savings and loans (S\&L) crisis; the 1998 Asian financial crisis; and the 2007 subprime mortgage crisis. During these episodes, policymakers implemented expansionary monetary policies to alleviate financial stress and help move the economy towards recovery. As such, there is clear interest for policymakers in having a better understanding of the impact of these high financial stress episodes on the transmission mechanism of monetary policy and the macroeconomy.

This paper aims to examine the impact and effectiveness of conventional monetary policy via various transmission mechanism channels during periods of low and high financial stress in the US economy. A Threshold Vector Autoregression (TVAR) model is employed to capture the asymmetries in the effects of monetary policy on the US economy corresponding to a switch between the low and high financial stress regimes. The use of a TVAR framework implies that a threshold variable has to be chosen to endogenize the regime-switching. Since the focus of this paper is on analyzing the nonlinear relationship between financial sector developments and the transmission of monetary policy shocks, the choice of the threshold variable has been the financial conditions index. The economy is in the high financial stress regime if the financial stress conditions are higher than the estimated threshold value. Conversely, the economy is in the low financial stress regime if the financial stress conditions are lower than the estimated threshold value.

Using the TVAR framework, there are three questions that are the focus of investigation in this paper.

1. Do monetary policy shocks have different effects under the influence of the low and high financial stress regimes?

2. Do monetary policy shocks of different magnitudes have asymmetric output effects on the real economy?

3. If the economy is in a low financial stress regime, do increases in the federal funds rate (FFR) increase the probability of moving into the high financial stress regime? 
The empirical literature that analyzes the asymmetric effects of monetary policy on the economy mainly focuses on investigating the asymmetries of the effects of monetary policy in a business cycle context (i.e. in a recession and an expansion) using variants of the Vector Autoregression (VAR) frameworks. Examples include Weise (1999), Garcia and Schaller (2002), Kaufmann (2002) and Peersman and Smets (2002). So far, the empirical literature examining the role that financial market developments play in explaining macroeconomic dynamics and business cycles has been limited. For example, Balke (2000) uses the TVAR framework and US data to examine the role of credit in monetary policy transmission. The study emphasizes the findings in previous studies that the interest rate pass-through at different stages of the credit cycle is asymmetric and contractionary shocks appear to have a greater impact than expansionary ones.

Research employing analysis similar to that conducted in this paper was undertaken by Hubrich and Tetlow (2012). The authors analyze the impact of financial stress for the US macroeconomy by estimating a Markov-switching Vector Autoregression model using Bayesian methods. The main findings from Hubrich and Tetlow (2012) suggest that there is evidence of nonlinearities in the relationship between financial stress and the US macroeconomy. The response of output to financial shocks is also found to be different during periods of high financial stress and in normal times, which are periods of low financial stress. Hence, this paper aims to bridge the gap in the literature by estimating a TVAR model to capture the asymmetries in the impact of conventional monetary policy shocks in the US, dependent on the financial conditions. Use of the financial conditions index provides a more comprehensive measure of the financial conditions in the US economy, compared to the single credit measure condition used in previous studies.

Various theoretical papers have analyzed the asymmetric relationship between financial sector developments, economic activity and the transmission mechanism channels of monetary policy shocks. Recent theoretical literature places emphasis on the nonlinear dynamics in these relationships. Specifically, the hypothesized nonlinearity in monetary policy in a financial setting is closely linked to the financial accelerator mechanism, introduced in Bernanke and Gertler (1989).

The financial accelerator mechanism is defined as the nonlinear inverse relationship between the external finance premium (EFP) that borrowers have to pay when they seek external funding and the credit rating of the borrower. The nonlinearity in this relationship arises from the effects of the financial accelerator, which is expected to 
be stronger when the net worth of borrowers is lower. During periods of low financial stress, firms and households have ample internal funds and mostly do not require external funding. Moreover, the risk premium associated with bankruptcy during periods of low financial stress is low. During periods of high financial stress, a decline in cash flow implies that firms and households have to seek external funding. The increase in risk premium associated with bankruptcy and the low net worth of these borrowers during periods of high financial crisis implies that any changes in monetary policy directly translates to large changes in the cost of credit.

Bernanke and Gertler (1989) explore the possibility of a nonlinear credit channel of monetary policy by developing a two-sector model that allows allow for the financial accelerator effects, where negative shocks in the balance sheet have a greater impact on the economy than positive shocks in the balance sheet. The financial accelerator concept was empirically tested in Bernanke, Gertler, and Gilchrist (1996), which was also incorporated into the dynamic general equilibrium model developed by Bernanke, Gertler, and Gilchrist (1999). The possibility of a nonlinear credit channel of monetary policy has also been noted in the literature by Azariadis and Smith (1998) and Ravn (2012).

Azariadis and Smith (1998) consider the relationship between credit and production in a simple nonmonetary overlapping generations model with production introduced and showed it is possible for two equilibrium financial regimes to exist. The authors develop a model that allows an economy to switch endogenously between a financially constrained regime that has heightened financial stress conditions, such as higher interest rates, and a deterioration of balance sheets of firms, and a financially unconstrained regime under reduced financial stress conditions. Ravn (2012) built a Dynamic Stochastic General Equilibrium (DSGE) model with an explicit role for asset prices through the financial accelerator developed by Bernanke and Gertler (1989), assuming asymmetry in the relationship between the financial accelerator and the net worth of firms. The asymmetric financial accelerator is modelled by assuming different values of the elasticity of the external finance premium with respect to the net worth of firms. Therefore, when the entrepreneurs' wealth is already low, such as during financial crises, the external finance premium reacts more strongly to small changes in net worth.

Another monetary transmission channel closely linked to the credit channel of monetary policy is the supply-side cost channel advanced by Barth and Ramey (2001). The 
cost channel explains two empirical puzzles. First, it provides a complementary means to explain the observed larger output effect of monetary policy shocks during periods of high financial stress compared to periods of low financial stress. Second, the price puzzle often observed in standard Vector Autoregression (VAR) models can also be explained. This is made possible by allowing monetary policy shocks to have demand and supply side effects.

The cost channel hypothesis heavily relies on the role of net working capital in the production process. The net working capital consist of inventories and trade receivables, net trade payables. There is a general consensus that interest rate and credit conditions can affect firms' long run ability to invest in fixed capital and produce final output. However, the authors argue that changes in the interest rate and credit conditions can also affect firms' ability to produce final output by investing in net working capital. Insights from the credit channel help to better explain the cost channel mechanism. During periods of high financial stress with falling demand, firms are likely to be accumulating inventories, resulting in an increase in the stock of net working capital. With a decline in cash flow, firms are forced to turn to external funding. During periods of low financial stress, the opportunity cost of internal funds increases directly with the federal funds rate. However, during periods of high financial stress when firms are forced to seek external funding, the marginal cost of financing increases substantially and in a nonlinear manner as described by the credit channel, due to information asymmetry in the credit markets. The increase in the cost of external financing result in an increase in the marginal cost of production for firms, which corresponds to a direct increase in prices. Using aggregate and industry level US data, Barth and Ramey (2001) also provide evidence supporting the existence of a cost channel in the US over the last 40 years, with a contractionary monetary policy shock increasing the price/wage ratio in a VAR model. Apart from Barth and Ramey (2001), there are other credit channel related empirical studies in the literature that suggest the possibility of a cost channel of monetary policy. Examples include Farmer (1984), Christiano and Eichenbaum (1992) and Christiano, Eichenbaum, and Evans (1997).

The empirical results in this paper provide several insights into the relationship between the financial sector developments and the US economy. First, there is evidence of nonlinearity, dependent on financial stress conditions. Second, strong evidence has been found of the existence of the credit channel and financial accelerator mechanism during periods of high financial stress, where the output response to monetary policy 
shocks is larger than periods of low financial stress. This finding implies that monetary policy shocks can be both effective and potent for the US economy during financial crises. Third, the exchange rate channel effect, alongside expansionary monetary policy shocks, play an important role in helping the economy to recover when it is in a high financial stress regime. Fourth, there is evidence of an increase in prices, consistent with a cost channel effect, during periods of high financial stress. No dominant cost channel effect is found during periods of low financial stress. This implies that there is a worsening of the short run output-inflation trade off during financial crises when policymakers are likely to be conducting expansionary monetary policies. Hence, the optimal course of monetary policy during financial crises should take into consideration this short run output-inflation trade off. Last, the empirical findings also suggest that large contractionary monetary policy shocks can increase the likelihood of the economy moving from a low financial stress to high financial stress regime by a substantial amount. Likewise, large expansionary monetary policy shocks increase the likelihood of moving the economy out of a high financial stress regime.

An extension of the end of the sample to include periods of the subprime mortgage crisis and the Great Recession provide interesting results. Expansionary monetary policy during periods of high financial stress when the prevailing interest rate is at the zero lower bound has continued to be effective, through the lowering of interest rates and credit spreads, and shifting the US economy from a high financial stress to a low financial stress regime. However, as the interest rate is at the zero lower bound, there is no evidence that big expansionary monetary policy shocks are more effective than small expansionary monetary policy shocks. The output-inflation trade off persists in this extended sample, providing evidence of a dominant supply-side cost channel effect during periods of high financial stress.

The paper is organized as follows. Section 2 introduces the empirical model. Section 3 provides information on the estimation method and the nonlinearity test conducted. Section 4 presents the empirical results. Section 5 concludes.

\section{Empirical specifications}

\subsection{Model}

A Threshold Vector Autoregression (TVAR) approach is used in this paper to examine the asymmetric reactions to monetary policy shocks in the low and high financial stress 
regimes. The paper closest to the approach taken here is Balke (2000). As the main objective of this paper is to examine monetary policy asymmetries in the low and high financial stress regimes, the threshold variable used in the model is the financial conditions index. In the TVAR model estimated in this paper, there are two regimes, the low and high financial stress regimes, defined by a boundary which is equal to certain value of the threshold variable. The TVAR model allows regime switching to take place. The coefficients of the TVAR system are specific to each regime, where the process within each regime can be described by a linear model. The TVAR model can be described as follows in equation 1 ,

$$
Y_{t}=B_{1}+\gamma_{1}(L) Y_{t}+\left(B_{2}+\gamma_{2}(L) Y_{t}\right) I\left(y_{t-d}^{*}>\theta\right)+\epsilon_{t}
$$

where $Y_{t}$ is a vector containing US data for real GDP, inflation, the commodity price index, federal funds rate, financial conditions index and the exchange rate. Real GDP, the commodity price index and the exchange rate are in percentage log-deviations from a deterministic trend. $I$ is an indicator function that equals one if the threshold variable $y_{t}^{*}$ at lag order $d$ (the delay parameter) is greater than the threshold $\theta$ and zero otherwise. The delay parameter $d$ implies that if the threshold variable $y_{t-d}^{*}$ crosses the threshold value of $\theta$ at time $t-d$, the dynamics actually change at time $t$. The lag polynomials $\gamma_{1}(L)$ and $\gamma_{2}(L)$ describe the dynamics of the TVAR system. With the threshold variable $y_{t-d}^{*}$ as a function of US financial conditions, which is an element in $Y_{t}$, the TVAR describes both the evolution of $Y_{t}$ and that of the financial stress regimes. This implies that shocks to the federal funds rate can determine whether the economy moves to a low or high financial stress regime.

By construction, the TVAR model implies that heteroskedasticity can be assumed across the two regimes as the process within each regime can be described by a linear model as in equation 2 ,

$$
Y_{t}=B_{1}+\gamma_{1}(L) Y_{t}+\epsilon_{1, t}+\left(B_{2}+\gamma_{2}(L) Y_{t}+\epsilon_{2, t}\right) I\left(y_{t-d}^{*}>\theta\right)
$$

\subsection{Data and specification issues}

Quarterly data for the time period spanning 1973Q1-2008Q4 are used in this paper. As the main objective of this paper is to analyze the impact of conventional monetary policy that is not constrained by the zero lower bound of the federal funds rate, data after 2008 has been excluded from the baseline estimation. The federal funds rate 
hit the zero lower bound of 50 basis points since 2009Q1. ${ }^{1}$ The data consists of six variables that assume the following recursive causal ordering: Real GDP $\left(G D P_{t}\right)$; inflation $\left(I N F_{t}\right)$; the commodity price index $\left(C P_{t}\right)$; the federal funds rate $\left(F F R_{t}\right)$; the Adjusted National Financial Conditions Index $\left(F C I_{t}\right)$; and the exchange rate $\left(E X_{t}\right)$. Table A1 in Appendix A provides more information on the source of the data used in this paper. All variables are made stationary prior to the estimation of the TVAR. Hence, real GDP, the commodity price index and the exchange rate variables are defined in percentage log-deviations from a deterministic trend, and inflation is the annualized inflation rate. The chosen lag length of the TVAR model is one lag, determined by the Schwarz information (SC) and Hannan-Quinn (HQ) information criteria.

\subsection{Transition variable}

The transition variable is chosen to be the ANFCI is constructed based on 100 indicators of financial activity by the Chicago Federal Reserve. The ANFCI provides a broad overview of US financial conditions in terms of risk, liquidity and leverage in money markets and debt and equity markets as well as in the traditional and 'shadow' banking systems. As US economic and financial conditions tend to be highly correlated, the ANFCI is constructed in a manner such that the index provides an update on the financial conditions relative to current economic conditions. A positive ANFCI value implies that financial conditions are tighter than would typically be suggested by economic conditions, while a negative value implies the opposite.

\section{TVAR model estimation and non-linearity tests}

The TVAR model is estimated by ordinary least squares (OLS). Prior to estimating the TVAR model, the threshold of the switching variable is either arbitrarily fixed or estimated from the model. In this analysis, the threshold is determined endogenously by a grid search over possible values of the threshold variable. The grid is constructed such that 20 percent of the upper and lower bound values are trimmed to ensure there are at least a minimum of 48 observations in each regime. ${ }^{2}$ Based on the constructed grid,

\footnotetext{
${ }^{1}$ The policy interest rate cannot be exactly zero as there would be various transaction costs detailed in Oda and Okina (2001). Krugman (1998) argues that a nominal rate of 0.43 percent is a good approximation of an economy that is facing liquidity trap conditions. Studies in the literature typically choose 50 basis points to be the zero lower bound (e.g., Iwata and Wu (2006)).

${ }^{2}$ The level of trimming of the grid is chosen arbitrarily. The standard level of trimming often used in the existing literature is between 15 and 20 percent.
} 
the estimated threshold value corresponds to the estimated model with the smallest determinant of the variance-covariance matrix of the estimated residuals:

$$
\theta^{*}=\underset{\theta}{\operatorname{argmin}} \log \left|\Omega_{\epsilon}(\theta)\right| .
$$

The estimated threshold value for the financial conditions index is 0.2630 . To put this threshold value into perspective, Figure 1 plots the financial conditions index and its estimated threshold value. The estimated threshold value of 0.2630 accurately identifies some of the major high financial stress periods such as the Asian financial crisis in 1997 and the subprime mortgage crisis in 2007.

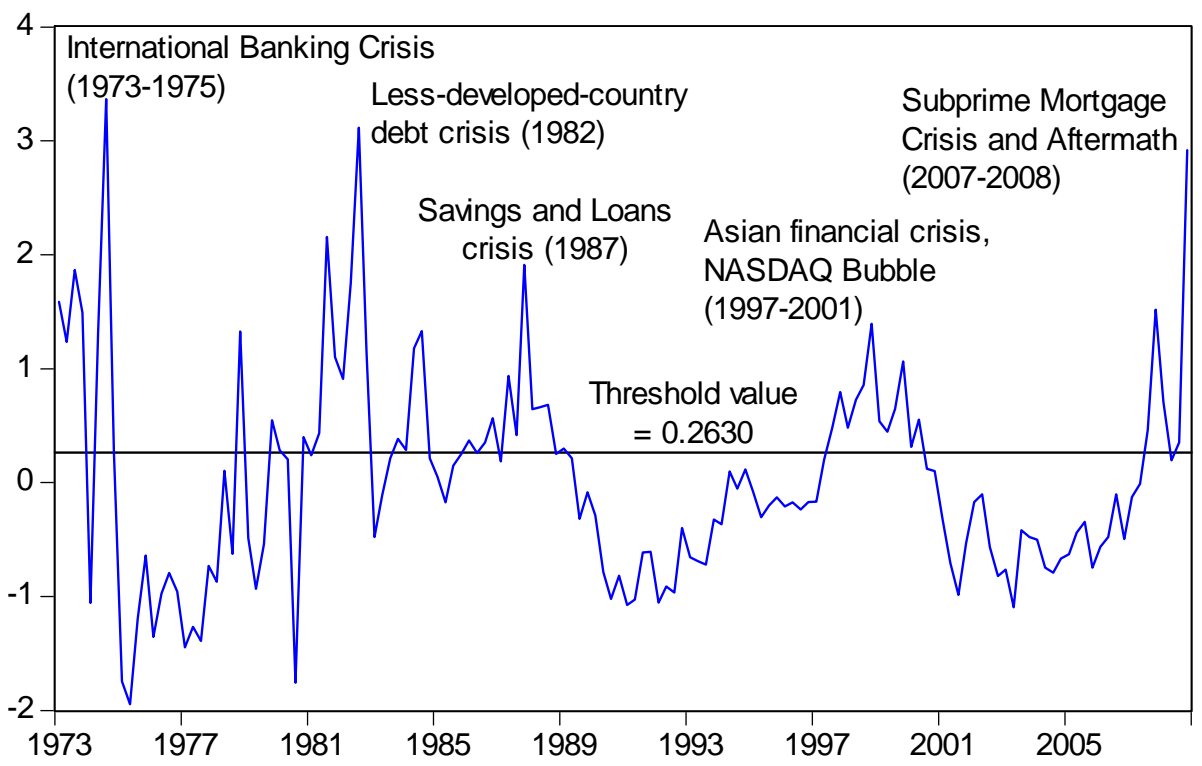

Figure 1: The financial conditions index and its estimated threshold value (0.2630).

It is also important to test if the chosen threshold value is meaningful by employing non-linearity tests to each equation of the TVAR system. The null hypothesis is that the coefficients of $B_{2}$ and $\gamma_{2}(L)$ equal zero is expressed in equation 3 as follows:

$$
H_{0}=B_{2} \text { and } \gamma_{2}(L)=0 .
$$

When the threshold is known, the null hypothesis can be tested using a Wald test. In this paper, the threshold is not identified under the null. Hence, according to Hansen (1996), standard inference cannot be applied and asymptotic p-values need to be derived. 
Let $W^{*}$ be the sup-Wald statistic of all possible statistics over the grid:

$$
W^{*}=\sup _{\theta} W(\theta) .
$$

As $\theta$ is not identified under the null hypothesis, the distribution of this sup-Wald statistic does not follow a $x^{2}$ distribution. Asymptotic p-values are derived from the empirical distribution for the sup-Wald statistic using the bootstrap procedure of Hansen (1996, 1997).

Non-linearity is tested for each equation of the TVAR system. Table 1 presents the non-linearity test results of a linear VAR against a threshold alternative for each equation of the TVAR system. The non-linearity test results show that the real GDP equation display threshold effects. Hence, there is evidence that the financial conditions index is an appropriate threshold variable. More importantly, the non-linearity tests provide evidence that the estimated threshold value is meaningful in separating the high financial stress regime from the low financial stress regime which are statistically different from one another.

Table 1: Asymptotic p-values for sup-Wald statistics of non-linearity tests

\begin{tabular}{lllllll}
\hline & \multicolumn{5}{c}{ Threshold variable: Financial conditions index } \\
\hline Equation & Real & Inflation & $\begin{array}{l}\text { Commodity } \\
\text { price } \\
\text { index }\end{array}$ & $\begin{array}{l}\text { Federal } \\
\text { funds } \\
\text { rate }\end{array}$ & $\begin{array}{l}\text { Financial } \\
\text { conditions } \\
\text { index }\end{array}$ & $\begin{array}{l}\text { Exchange } \\
\text { rate }\end{array}$ \\
\hline p-values & 0.046 & 0.182 & 0.189 & 0.125 & 0.746 & 0.730 \\
\hline
\end{tabular}

\section{Empirical results}

Impulse response analysis is conducted to investigate the asymmetric effects of monetary policy shocks in the low and high financial stress regimes. This section uses impulse response analysis to answer two questions. First, do monetary policy shocks have different effects in the low and high financial stress regimes? Second, do monetary policy shocks of different magnitudes have asymmetric effects on the real economy, particularly on output? To answer these two questions, two sets of impulse responses are constructed - regime-dependent impulse responses and nonlinear impulse responses.

In the first set of impulse responses, the economy is assumed to remain within the respective regime which was in place when the shock initially hits. Given that the process within each regime can be described by a linear model, the regime-dependent 
impulse responses can be obtained by using the estimated coefficients for each regime. These impulse responses are linear in shocks and are history independent. Regimedependent impulse responses are useful in describing the behavior of the economy within each regime. However, using regime-dependent impulse response functions may not be sufficient to analyze the overall impact of a shock to the economy, particularly where a shock to the federal funds rate can result in a change in the financial conditions, resulting in a switch in regime.

Therefore, the second set of impulse response functions relaxes the above assumption that the economy remains in the same regime prevailing at the time of the shock. In this second set of impulse response functions, the economy is allowed to move from one regime to another. In particular, a shock to the federal funds rate can generate movements in the threshold variable, the financial conditions index, which then induce regime-switching over the forecast horizon. When the system is allowed to switch between regimes, the impulse response functions depend on the initial state, size and sign of the shock. In order to measure the impulse responses when the threshold variable is allowed to respond endogenously, this paper computes the nonlinear impulse response functions following Koop, Pesaran, and Potter (1996).

\subsection{Regime-dependent impulse responses}

Given that the process within each regime can be described by a linear model, the regime-dependent impulse responses can be obtained by using the estimated coefficients for each regime. These impulse responses are linear in shocks and are history independent.

The impulse responses demonstrated during low financial stress and high financial stress regimes as a result of a 1 standard deviation decline in the federal funds rate, assuming that the economy stays in the regime prevailing at the time of the shock are shown in Figure ??. All the impulse responses shown are cumulated responses, except for the federal funds rate.

A decline in the federal funds rate leads to an increase in output, loosening of financial conditions and an eventual depreciation in the exchange rate in both the low and high financial stress regimes. Inflation increases in the low financial stress regime as expected with the increase in output. A price puzzle is observed in the high financial stress regime, with inflation declining for a few quarters before increasing.

A closer look at the impulse responses reveals significant differences across regimes. 

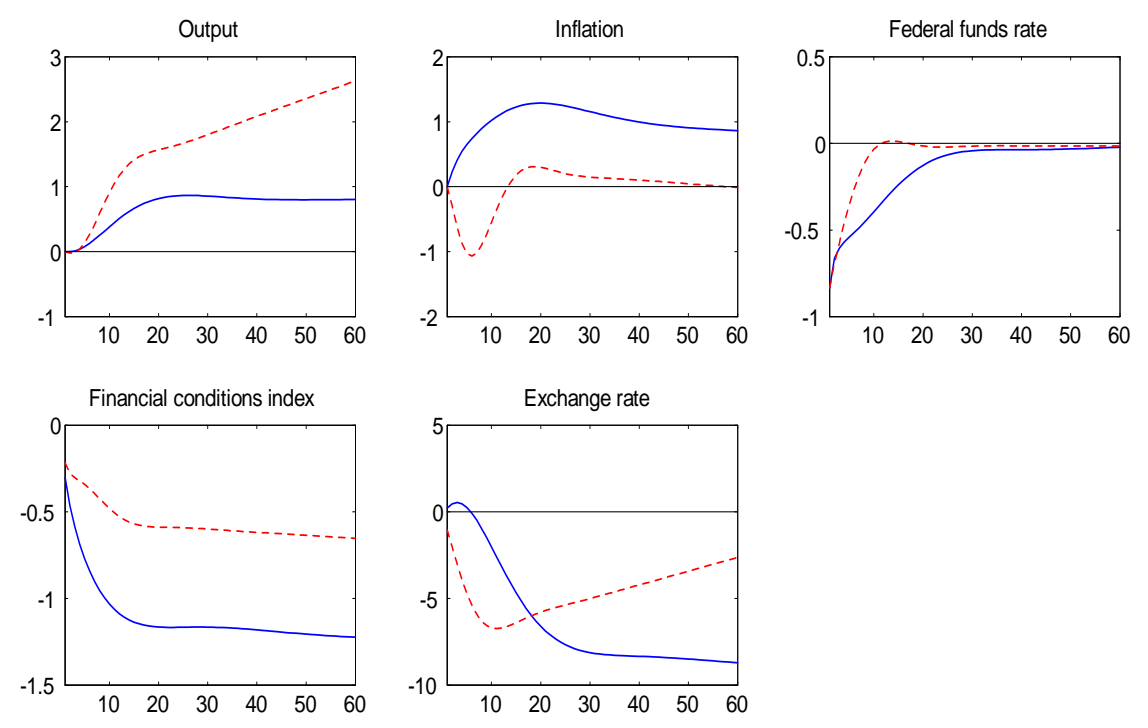

Figure 2: Impact of a 1 standard deviation decline in the federal funds rate in the low and high financial stress regimes.

Note: Solid lines refer to low financial stress regimes. Dotted lines refer to high financial stress regimes.

First, the magnitude of the impulse responses differs strongly. The cumulated response in output increases by much more in the high financial stress regime than in the low financial stress regime. This is an indication that the financial accelerator effect as described in Bernanke and Gertler (1989), Gertler and Gilchrist (1994) and Bernanke, Gertler, and Gilchrist (1996) may be in place. The financial accelerator effect is expected to be stronger during financial crises when entrepreneurs' wealth is low. More specifically, through the bank lending and balance sheet transmission channels, a monetary expansion that takes place in a high financial stress regime is expected to result in a larger increase in asset prices and larger decline in the external cost of funding (the external finance premium) than in the low financial stress regime. This implies that variables that describe the real economy such as output and inflation are expected to increase more in a high financial stress regime than in a low financial stress regime. This observation is similar to the results found by McCallum (1991), where the author finds that money supply shocks have a larger impact on output during periods in which the economy is experiencing tight credit circumstances. This finding and the results in McCallum (1991) are also consistent with the hypothesis put forward in Blinder (1987), where a tightening of monetary policy has stronger effects on the real economy 
when the credit is already tight but weak effects when credit is initially abundant.

Second, the standard exchange rate channel effects can be observed from the eventual depreciation of the exchange rate in both high and low financial stress regimes. However, following the decline in the federal funds rate, the depreciation of the exchange rate in the high financial stress regime has been immediate, but gradual in the low financial stress regime. This difference in the reaction of the exchange rate suggests that the exchange rate plays a particularly important role in boosting the economy during periods of high financial stress.

Third, the observation of an initial decline in inflation in the high financial stress regime and not in the low financial stress regime is consistent with the cost channel effect suggested by Barth and Ramey (2001). When the economy is in a high financial stress regime with constrained credit, demand within the economy is expected to decline. The decline in demand means that firms are faced with accumulating inventories and accounts receivable as well as falling cash flow. Firms are forced to seek external financing due to the decline in internally generated funds as the stock of working capital rises. Insights from the credit channel suggest that a monetary expansion in a high financial stress regime decreases the cost of external financing by more than in a low financial stress regime. In fact, during periods when the financial stress is low, changes in monetary policy should not influence the cost of credit for borrowers wide internal finance. This implies that firms' interest expenses on working capital and hence marginal cost of production and output prices are expected to decrease by much more in a high financial stress regime than in a low financial stress regime. Therefore, the expansionary monetary policy shock that may initially work through the demand channel may be propagated through the supply side channel eventually. The existence of a cost channel effect during financial crises when policymakers are likely to be conducting expansionary monetary policies suggests a worsening of the short run output-inflation trade off.

\subsection{Nonlinear impulse responses}

Regime-dependent impulse responses are useful in describing the behavior of the economy within each regime. The regime-dependent impulse responses in the previous section provides a clear indication of the differences in responses across regimes. However, using regime-dependent impulse response functions may not be sufficient to analyze the overall impact of a shock to the economy, particularly where a shock to the federal 
funds rate can result in a change in the financial conditions, resulting in a switch in regime. Therefore, the second set of impulse response functions computed relaxes the above assumption that the economy remains in the same regime prevailing at the time of the shock.

In this second set of impulse response functions, the economy is assumed to be in one of the two regimes, and are thus history-dependent. A shock to the federal funds rate can result in changes in the threshold variable, the financial conditions index, which then induce regime-switching over the forecast horizon. When the system is allowed to switch between regimes, the impulse response functions are sensitive to initial state, size and sign of the shock, and are thus shock-dependent. In order to measure the impulse responses when the threshold variable is allowed to respond endogenously, this paper computes the nonlinear impulse response functions following Koop, Pesaran, and Potter (1996). Appendix B and C provide further information on the algorithm used to compute the nonlinear impulse response functions and the confidence bands respectively. The confidence bands calculated based on the nonlinear impulse responses are available in Appendix D.

The nonlinear impulse response of a variable $y$ at horizon $n$ can be defined as the differences in two conditional expectations due to a shock at time $t$, dependent on the economy being in a particular regime. This nonlinear impulse response is denoted in equation 5 ,

$$
I R F_{y}\left(n, u_{t}, \Omega_{t-1}\right)=E\left[y_{t+n} \mid \Omega_{t-1}, u_{t}\right]-E\left[y_{t+n} \mid \Omega_{t-1}\right],
$$

where $\Omega_{t-1}$ is the information set at time $t-1$. The size and sign of the shock and the initial conditions of the regime that the economy is starting in, $\Omega_{t-1}$, are required to calculate the impulse responses. The conditional expectations $E\left[y_{t+n} \mid \Omega_{t-1}, u_{t}\right]$ and $E\left[y_{t+n} \mid \Omega_{t-1}\right]$ are computed by simulating the model.

The nonlinear impulse responses can be simulated through the following steps. First, shocks for periods 0 to 60 are simulated using the cholesky decomposition of the variance-covariance matrix for the TVAR model. For given initial values of the variables, these shocks are fed through the estimated model to produce a set of simulated data series. The result from this step is a forecast of the variables conditional on initial values and a particular sequence of shocks, denoted as the baseline forecast. Second, the same procedure is repeated with the same set of initial values and shocks, with the shock to the federal funds rate in period 0 fixed at 1 standard deviation. The 
shocks are fed through the model to obtain a forecast of the variables. The impulse response function for a set of initial values and particular sequence of shocks is then the difference between this forecast and the baseline forecast. This simulation is repeated for 500 draws of the shocks to allow the shocks to average out. Subsequently, these impulse response functions are averaged over the respective regime history to produce an impulse response function conditional only on initial values.

\subsection{Effects of monetary policy shocks under different financial stress regimes}

This section examines the impact of expansionary and contractionary monetary policies on the economy in the low and high financial stress regimes. Nonlinear impulse responses are not symmetric in their impulses. Hence, different impulse responses can be expected from examining the impact of expansionary and contractionary monetary policies on the economy in the low and high financial stress regimes.

\subsubsection{Expansionary monetary policy}

The impulse response functions to a 1 and 2 standard deviation decline in the federal funds rate in the low and high financial stress regimes respectively are shown in Figures ?? and ??. All the responses are cumulated responses except for the federal funds rate.

A 1 standard deviation decline in the federal funds rate eventually leads to an increase in output in the low and high financial stress regimes. However, in the high financial stress regime, output decreases initially before gradually increasing to a level above that of the response of output in the low financial stress regime. This finding reinforces the results from the earlier estimated regime-dependent impulse response. The financial conditions in both regimes loosen as expected.

The decrease in the federal funds rate implies that US dollar deposits become less attractive relative to deposits denominated in foreign currencies. This leads to a decline in the value of the US dollar relative to other currencies. Hence, the exchange rate depreciates in both regimes, with the exchange rate depreciating to a larger extent in the high financial stress regime. The greater depreciation in the exchange rate in the high financial stress regime is particularly helpful in boosting the economy when it is initially in the high financial stress regime. This finding once again suggest that the exchange rate effect plays an important role in the recovery of the economy during periods of high financial stress. 

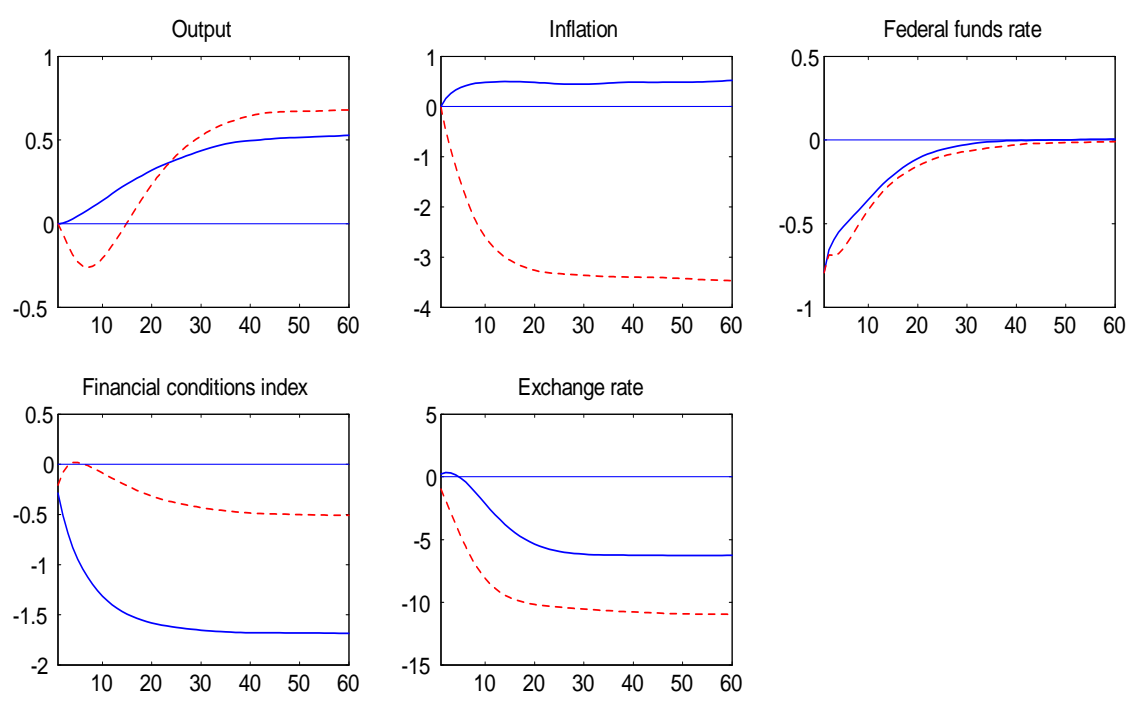

Figure 3: The effects of a 1 standard deviation decline in the federal funds rate at different initial states.

Note: Solid lines refer to low financial stress regimes. Dotted lines refer to high financial stress regimes.
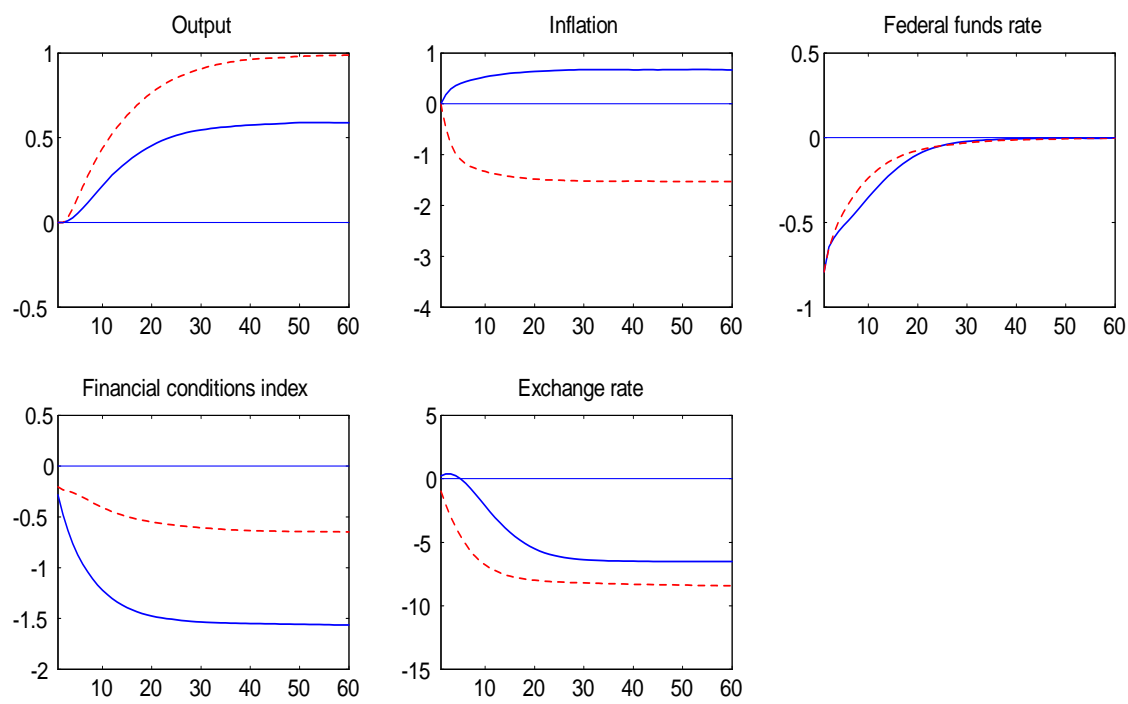

Figure 4: The effects of a 2 standard deviation decline in the federal funds rate at different initial states.

Note: Solid lines refer to low financial stress regimes. Dotted lines refer to high financial stress regimes. 
Inflation increases and decreases under the low and high financial stress regimes respectively. The increase in inflation in the low financial stress regime following the increase in output is consistent with the demand channel of monetary transmission. Similarly, the increase in inflation in the high financial stress regime once again confirms that the cost channel effect is in place during periods of high financial stress.

The impulse responses to a 2 standard deviation decline in the federal funds rate are similar in shape and signs to the impulse responses to a 1 standard deviation decline in the federal funds rate. However, the larger increase in output in the high financial stress regime compared to the low financial stress regime is clearer with a 2 standard deviation decline in the federal funds rate.

\subsubsection{Contractionary monetary policy}

Impulse response functions to a 1 and 2 standard deviation increase in the federal funds rate starting from an initial state of low and high financial stress are displayed in Figures ?? and ?? respectively. All the responses are cumulated responses except for the federal funds rate.

Following the increase in federal funds rate, output declines by more in the high financial stress regime compared to the low financial stress regime. This provides evidence that the credit channel effect exists during periods of high financial stress, regardless of the type of shock that takes place. Financial conditions tighten in both regimes.

The exchange rate appreciates in both regimes, with the appreciation in exchange rate stronger in the high financial stress regime than in the low financial stress regime. This difference in the appreciation of the exchange rate is more pronounced with a 2 standard deviation federal funds rate shock.

Inflation declines in both regimes, with a slight price puzzle observed in the high financial stress regime in the event of a 2 standard deviation increase in the federal funds rate. This observed price puzzle is consistent with a dominant cost channel effect due to an increase in the marginal cost of financing. Overall, inflation decreases more in the high financial stress regime than in the low financial stress regime, consistent with the larger decline in output observed in the high financial stress regime. Interestingly, there is generally no evidence of the price puzzle observed in the event of an expansionary monetary policy shock, as seen in Figures ?? and ??. Hence, this result points to the existence of a demand channel of monetary transmission in the event of 

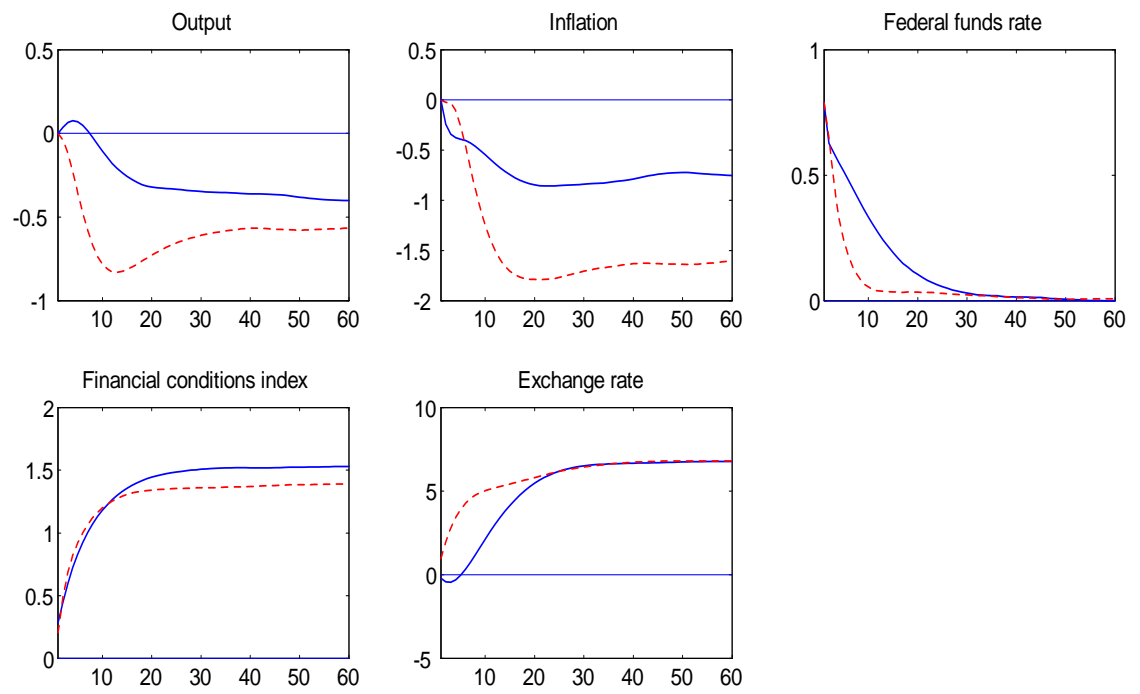

Figure 5: The effects of a 1 standard deviation increase in the federal funds rate at different initial states.

Note: Solid lines refer to low financial stress regimes. Dotted lines refer to high financial stress regimes.
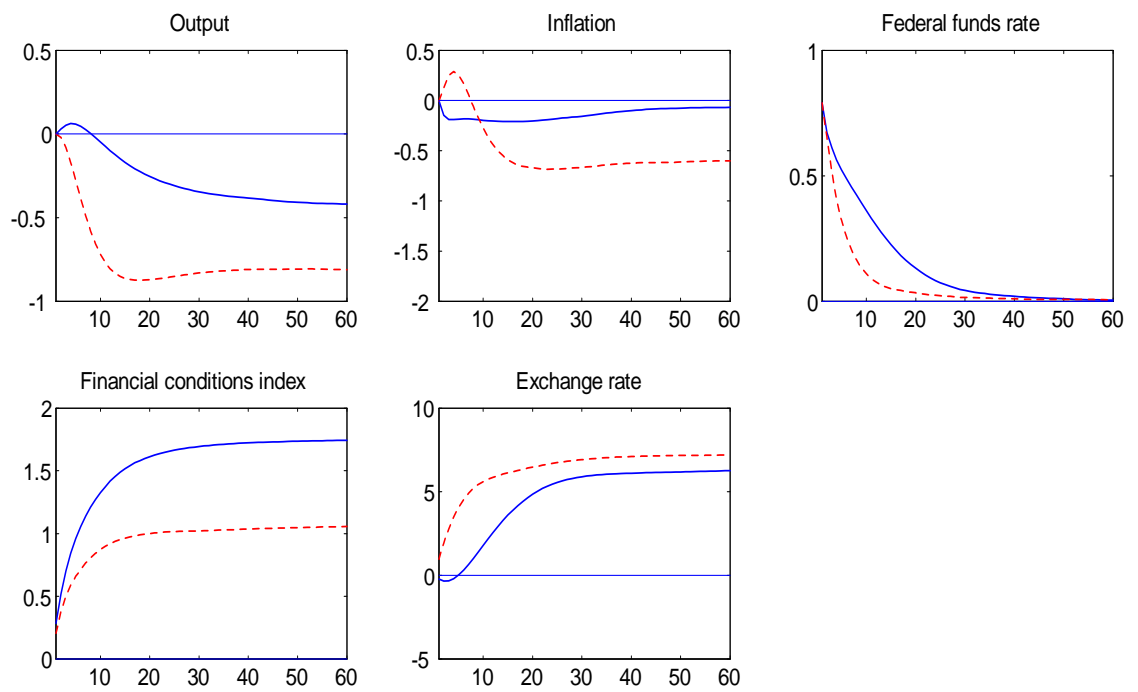

Figure 6: The effects of a 2 standard deviation increase in the federal funds rate at different initial states.

Note: Solid lines refer to low financial stress regimes. Dotted lines refer to high financial stress regimes. 
a contractionary monetary policy shock. While the price responses are indicative of a demand transmission channel of monetary policy, this does not imply that the cost transmission channel of monetary policy does not exist. Instead, it is likely that the demand channel effects dominate in this instance. Furthermore, the appreciation in the exchange rate also result in cheaper imported materials. Hence, any direct costside effects of a contractionary monetary policy may have been counteracted by the exchange rate effect.

\subsection{Effects of small versus large shocks of monetary policy}

This section looks at the impact of expansionary and contractionary monetary policy shocks of different magnitudes on output in different regimes. Understanding the effectiveness of monetary policies of different magnitudes on the economy in different regimes is of particular interest to policymakers.

\subsubsection{Expansionary monetary policy}

Impulse responses to 1 and 2 standard deviation decline in the federal funds rate in the low and high financial stress regimes are shown in Figures ?? and ?? respectively. Impulse responses for the 2 standard deviation shock are scaled down by a factor of two in order to allow direct comparison with the responses to a 1 standard deviation shock.

Overall, the impact of a 2 standard deviation decline in the federal funds rate on output is stronger than the 1 standard deviation decline in the federal funds rate, particularly in the high financial stress regime. This finding suggests that expansionary monetary policies, especially large expansionary monetary policies, are effective and more potent during financial crises, via the credit channel.

\subsubsection{Small versus large contractionary monetary policy}

Impulse responses to 1 and 2 standard deviation increase in the federal funds rate in the low and high financial stress regimes are shown in Figures ?? and ?? respectively. The responses of output to 1 and 2 standard deviation increase in the federal funds rate are similar in the low financial stress regime. In the high financial stress regime, the 2 standard deviation increase in the federal funds rate result in a notably larger decline in output compared to the 1 standard deviation increase in the federal funds 

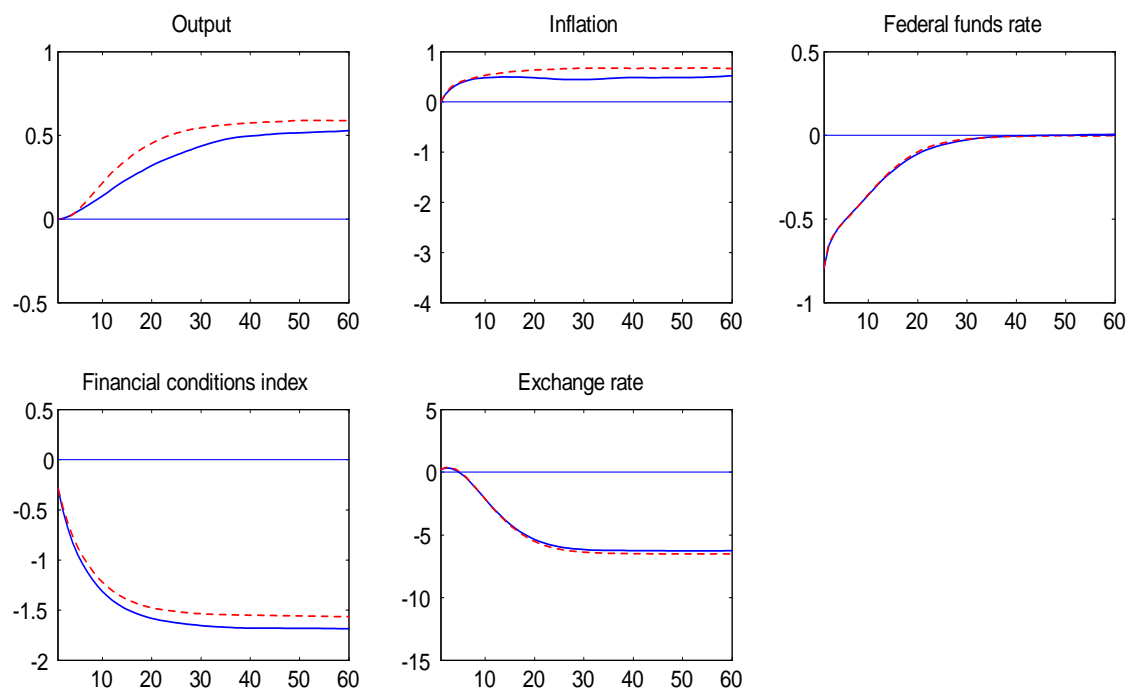

Figure 7: The effects of a 1 and 2 standard deviation decline in the federal funds rate in the low financial stress regime.

Note: Solid lines and dotted lines refer to the 1 and 2 standard deviation decline in the federal funds rate respectively.
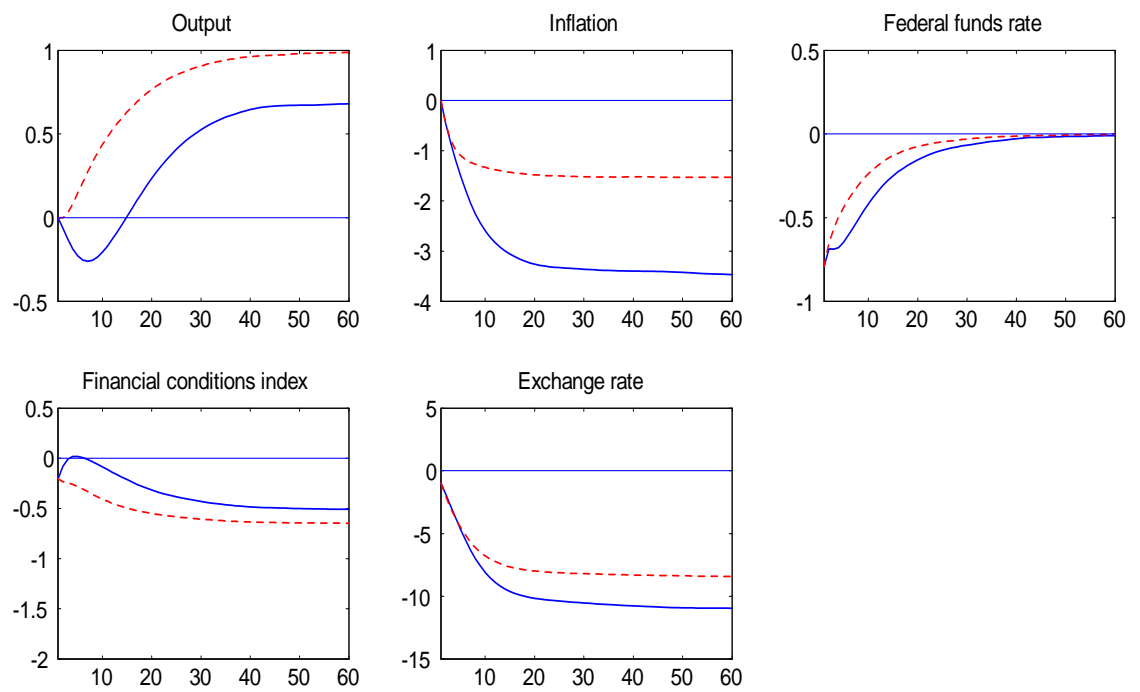

Figure 8: The effects of a 1 and 2 standard deviation decline in the federal funds rate in the high financial stress regime.

Note: Solid lines and dotted lines refer to the 1 and 2 standard deviation decline in the federal funds rate respectively. 
rate. This finding once again provides evidence on the presence of the credit channel effect during financial crises.
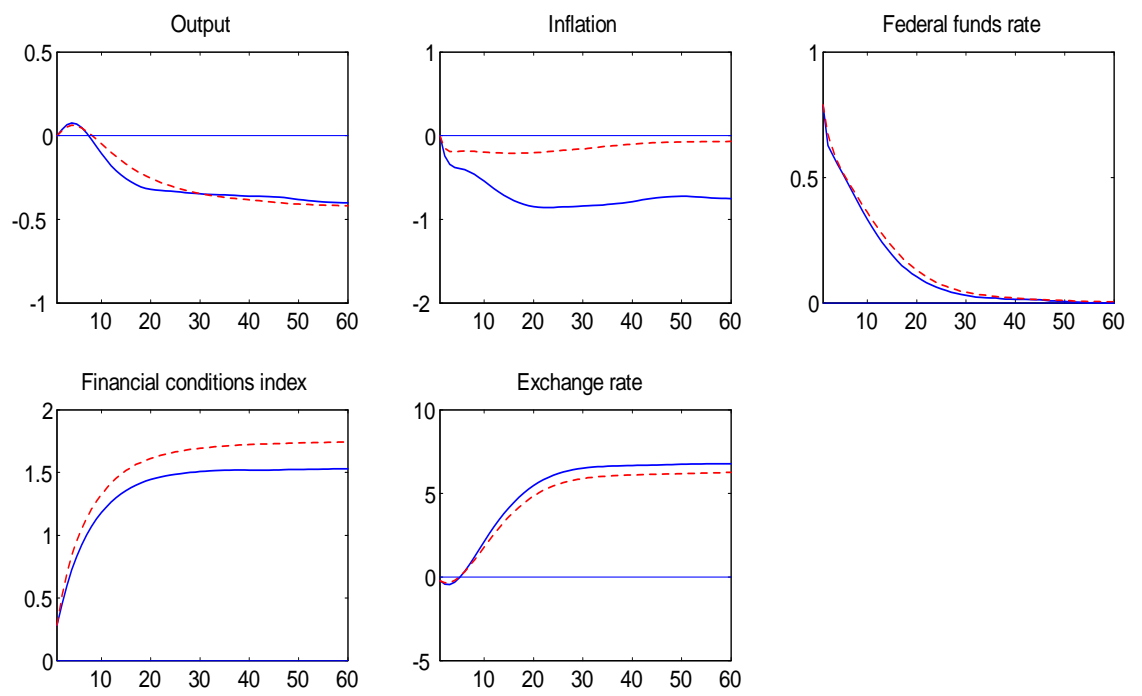

Figure 9: The effects of a 1 and 2 standard deviation increase in the federal funds rate in the low financial stress regime.

Note: Solid lines and dotted lines refer to the 1 and 2 standard deviation increase in the federal funds rate respectively.

\subsection{Extension of the sample to 2012Q4}

In this Section, the end of the sample is extended from 2008Q4 to 2012Q4 to analyze if the addition of the recent subprime mortgage crisis and the Great Recession periods has any impact on the asymmetric effects of monetary policy. The period from 2009Q1 to 2012Q4 is characterized by very tight financial conditions initially, and rapid loosening of the financial conditions for the rest of the extended sample. Inflation remained relatively stable while the federal funds rate has hit the zero lower bound over this extended sample period. ${ }^{3}$ The impulse responses from the estimations in this section are available in Appendix E.

The threshold value used in the estimations in this section is fixed at 0.2630 , which is the threshold value estimated in the baseline case using sample period of 1973Q1

\footnotetext{
${ }^{3}$ It is not possible for the federal funds rate to be exactly zero due to the various transaction costs. Krugman (1998) estimates that a nominal rate of 0.43 percent is an indication that the economy is in liquidity trap conditions.
} 

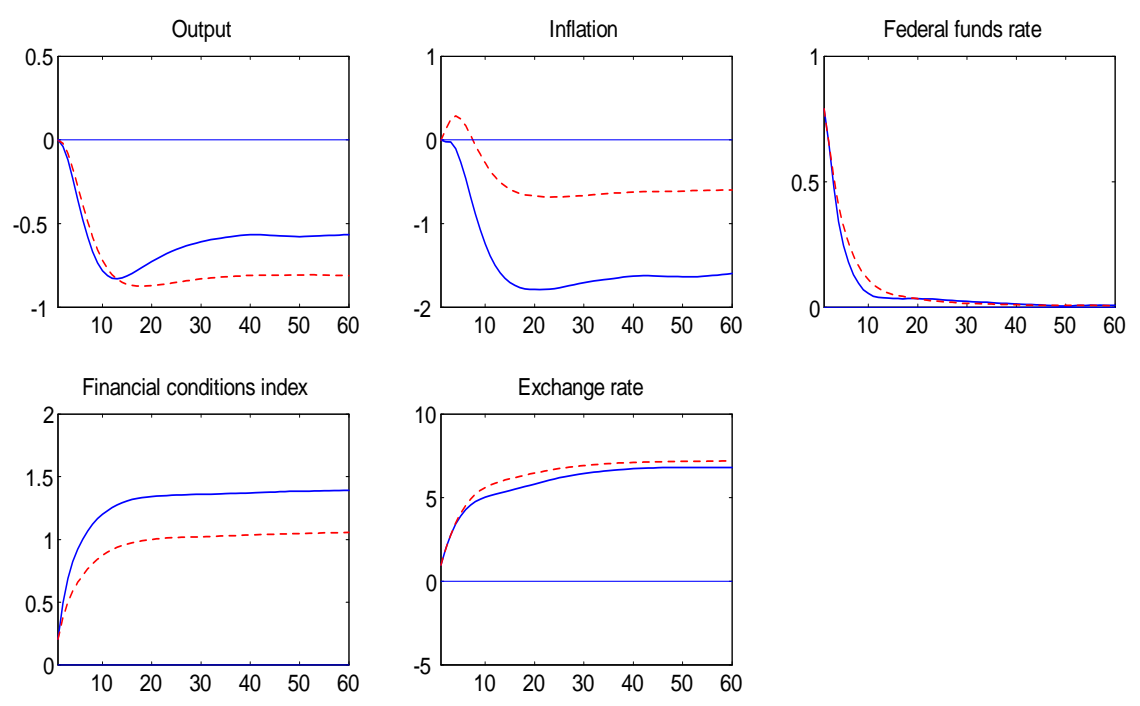

Figure 10: The effects of a 1 and 2 standard deviation increase in the federal funds rate in the high financial stress regime.

Note: Solid lines and dotted lines refer to the 1 and 2 standard deviation increase in the federal funds rate respectively.

to 2008Q4. There are two reasons for this. First, keeping the threshold value for the estimations at 0.2630 allows comparison with the baseline case. Second, the threshold value estimated using the new sample of 1973Q1 to 2012Q4 is at 0.3975, which is found to be insignificant using the nonlinearity test of Hansen (1996). The higher estimated threshold value also reduces the number of observations in the higher financial stress regime to 43 observations, below the minimum of 48 required in each regime to ensure stable estimations.

The results from the extended sample from 1973Q1 to 2012Q4 provide some interesting insights into the impact of the subprime mortgage crisis and the Great Recession on the asymmetric effects of monetary policy. First, the regime-dependent and nonlinear impulse responses suggest that the effects of expansionary and contractionary monetary policy shocks in the low and high financial stress regimes remain asymmetric. In particular, the response of output in the high financial stress regime remains larger than the response of output in the low financial stress regime, providing evidence on the nonlinear credit channel effect of Bernanke and Gertler (1989). This finding also emphasizes the results from the previous Section that expansionary monetary policy is more potent and effective during periods of high financial stress than in periods of low 
financial stress. The additional sample periods from 2009Q1 to 2012Q4 are periods marked by extremely low interest rates. According to Krugman (1998), such periods provide a 'good approximation to liquidity trap conditions', implying that the interest rate channel of monetary policy shocks is eliminated. However, as argued by Mishkin (2009), the extremely low prevailing interest rates can be useful, helping to lower the interest rates on default-free securities and to lower credit spreads. This helped to move the US economy from a high to a low financial stress regime, which contributed towards an improvement in economic performance.

Second, inflation increases in the presence of expansionary and contractionary monetary policy in the high financial stress regime. This observation provides unambiguous evidence of a dominant supply-side cost channel effect in the high financial stress regime. Previously, using sample from 1973Q1 to 2008Q4, inflation declined in the presence of contractionary monetary policy in the high financial stress regime. This suggests that the subprime mortgage crisis and the Great Recession periods reinforced the cost channel effect, leading to a worsening of the output-inflation trade off. This result is consistent with the high cost of credit reflected in the Baa corporate bond rates that have remained high during the extended sample period from 2009Q1 to 2012Q4 despite the extremely low federal funds rate.

Third, the response of output to small and large monetary policy shocks are similar in magnitudes in both the low and high financial stress regimes, implying that a large monetary policy shock is no different from a small monetary policy shock. In the previous Section, the response of output to large monetary policy shocks is found to be larger than the response of output to small monetary policy shocks. The constraint of the interest rates at extremely low levels in the extended sample from 2009Q1 to 2012Q4 is likely to have contributed to this result.

The estimation results in this Section emphasizes the effectiveness and potency of expansionary monetary policy during financial crises. At the same time, the findings also suggest the need to account for the worsening short run output-inflation trade off during financial crises.

\subsection{Impact of monetary policy shocks on the probability of regime switching}

In this Section, the impact of monetary policy shocks on the probability of transiting between the low and high financial stress regimes based on the initial sample of 1973Q1 
to 2008Q4 is examined. In particular, the following questions are of interest. First, suppose the economy is initially in the low financial stress regime, does a contractionary monetary policy shock increase the probability of moving from the low to high financial stress regime? Second, suppose the economy is initially in the high financial stress regime, does an expansionary monetary policy shock increase the probability of moving from the high to low financial stress regime?

The probability of the economy being in the low financial stress regime, given the information set, $\Omega_{t-1}$, at time $t-1$, and a particular realization of an exogenous shock $u_{t}$ at time $t$, is denoted as:

$$
P(\text { low financial stress regime })=P\left[I\left(y_{t-d}^{*} \leq \theta\right) \mid \Omega_{t-1}, u_{t}\right]
$$

Likewise, the probability of the economy being in the high financial stress regime is denoted as:

$$
P(\text { high financial stress regime })=P\left[I\left(y_{t-d}^{*}>\theta\right) \mid \Omega_{t-1}, u_{t}\right]
$$

The impulse response functions of the threshold variable are calculated for each observation in the initial regime. The probability of regime switching is estimated by calculating the number of times the switching variable crossed the threshold value of 0.2630. Specifically, the probabilities of regime switching for the economy starting in the low and high financial stress regimes can be computed respectively as in equations 8 and 9 in the following manner.

$$
P(\text { low financial stress regime })=\frac{1}{n} \sum_{i=1}^{n}\left[I\left(y_{t-d}^{*} \leq \theta\right) \mid \Omega_{t-1}, u_{t}\right],
$$

and

$$
P(\text { high financial stress regime })=\frac{1}{n} \sum_{i=1}^{n}\left[I\left(y_{t-d}^{*}>\theta\right) \mid \Omega_{t-1}, u_{t}\right] .
$$

Figure 11 displays the estimated empirical probability of transiting from the low financial stress to the high financial stress regime under various shocks, namely 1 and 2 standard deviation contractionary and expansionary monetary policy shocks, and the baseline case of a zero shock. The results suggest that large contractionary monetary policy shocks of 2 standard deviation can substantially increase the likelihood of the economy switching from the low to the high financial stress regime. In contrast, expansionary monetary policy shocks does not substantially decrease the likelihood of 


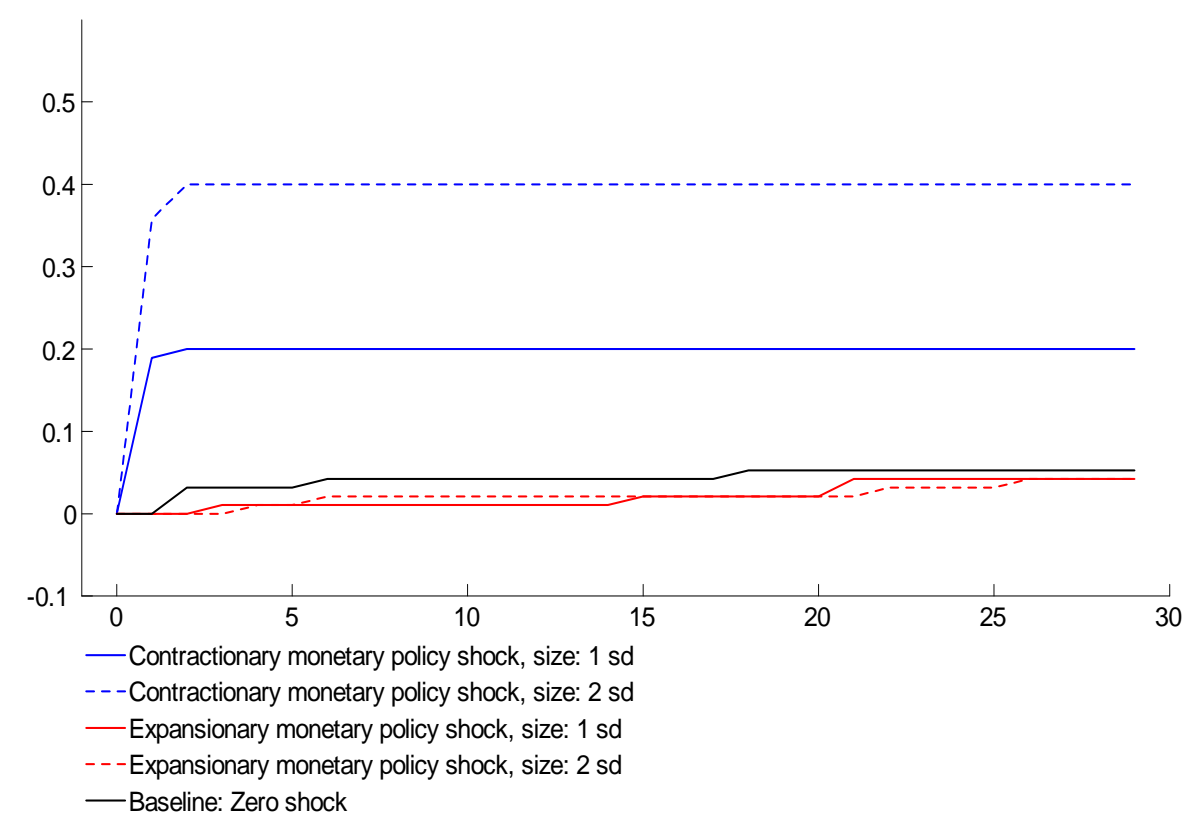

Figure 11: Empirical probability of switching from low to high financial stress regimes.

the economy switching to the high financial stress regime compared to the baseline case of a zero shock.

The estimated empirical probability of transiting from the high to the low financial stress regime are plotted in Figure 12. The findings show that expansionary monetary policy shocks, particularly large ones, can substantially increase the likelihood of the economy switching from the high to low financial stress regime. Therefore, large expansionary monetary policy shocks can be helpful in moving the US economy towards a recovery from financial crises. These results imply that monetary policy shocks play an important role in the endogenous regime switching between the low and high financial stress regimes.

\section{Conclusion}

The objective of this paper is to examine the asymmetry in the impact of conventional monetary policy through various transmission mechanism channels in different financial regimes, namely the low and high financial stress regimes, in the US economy. A Threshold Vector Autoregression model (TVAR), using financial conditions as the threshold variable, is estimated to capture the asymmetric effects of monetary policy and regime switching implied by the theoretical literature.

The empirical results shed some light on the relationship between financial sector 


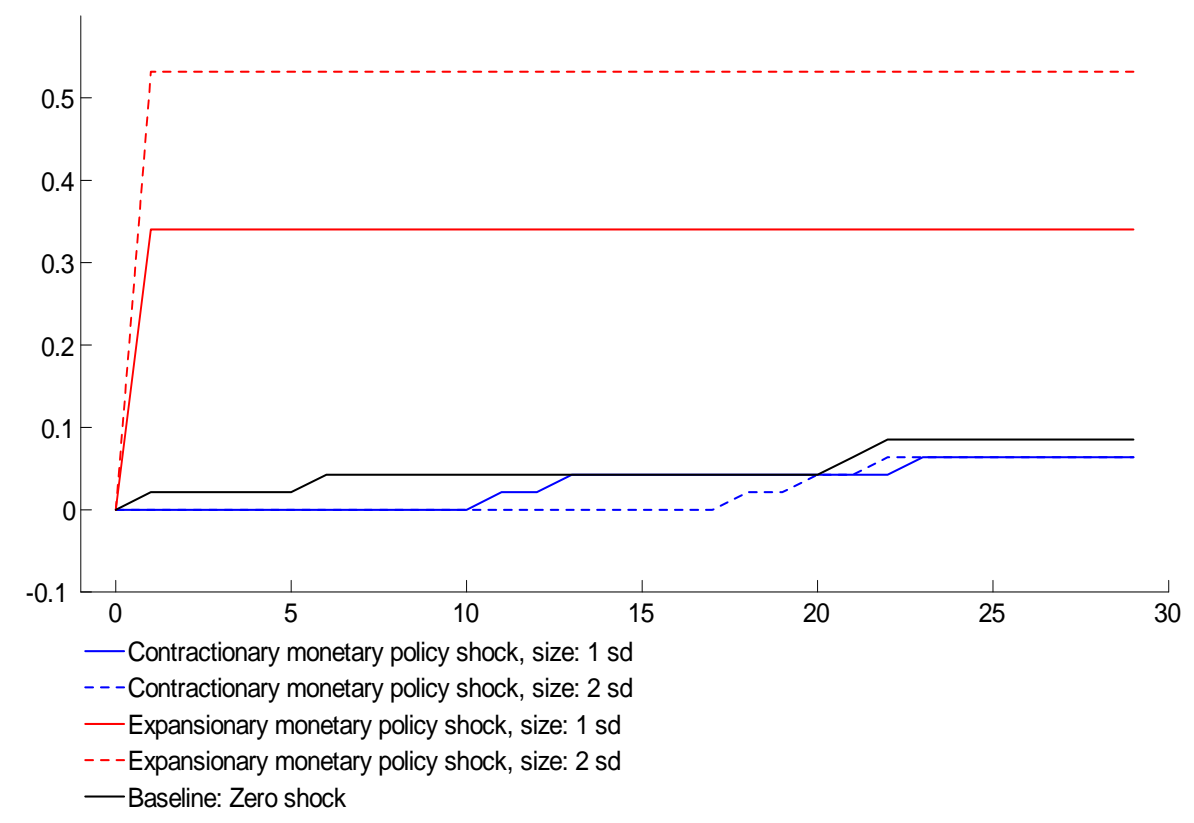

Figure 12: Empirical probability of switching from high to low financial stress regimes.

developments and the US economy. There is evidence of nonlinearity in the data, with a regime switch occurring if financial stress conditions reach the estimated threshold value. The findings in this paper generally suggest that monetary policy shocks play an important role in the US economy during financial crises. There is evidence of a greater output response to monetary policy shocks during periods of high financial stress. Large expansionary monetary policy shocks are also found to increase the likelihood of moving the economy out of a high financial stress regime. It is particularly interesting to note that there is evidence of a price puzzle only during periods of high financial stress. This price puzzle is consistent with the cost channel effect put forward by Barth and Ramey (2001), implying a worsening of the short run output-inflation trade off during financial crises when policymakers are more likely to implement expansionary monetary policies. The existence of a dominant cost channel effect during financial crises highlight the need for policymakers to carefully weigh the output-inflation trade off in the short run when deciding on the magnitude of expansionary monetary policies to implement in an attempt to guide the economy out of a financial crisis.

The extension of the end of the sample from 2008Q4 to 2012Q4 provide further evidence that expansionary monetary policy is more effective and potent during periods of high financial stress compared to periods of low financial stress. The results suggest that expansionary monetary policy during periods of high financial stress when prevail- 
ing interest rates are at the zero lower bound has continued to be effective likely due to the lower interest rates on default-free securities and lower credit spreads, shifting the US economy from a high financial stress to a low financial stress regime. The findings also provide unambiguous evidence of a dominant supply-side cost channel effect in the high financial stress regime, reinforcing the trade off between output and inflation during periods of high financial stress.

Future extensions of this empirical analysis will include examining the effectiveness of monetary policy when unconventional measures such as quantitative easing are used. This will involve explicitly accounting for the unconventional measures of monetary policy instruments that monetary authorities use. Future analyses will also extend this study to include more countries for comparison of experiences.

\section{References}

Azariadis, C. and B. Smith (1998). Financial Intermediation and Regime Switching in Business Cycles. The American Economic Review 88(3), 516-536.

Balke, N. S. (2000). Credit and Economic Activity: Credit Regimes and Nonlinear Propagation of Shocks. The Review of Economics and Statistics 82(2), 344-349.

Barth, M. J. and V. A. Ramey (2001). The Cost Channel of Monetary Transmission. NBER Macroeconomics Annual 2001 16, 199-255.

Bernanke, B. S. and M. Gertler (1989). Agency Costs, Net Worth, and Business Fluctuations. The American Economic Review 79(1), 14-31.

Bernanke, B. S., M. Gertler, and S. Gilchrist (1996). The Financial Accelerator and the Flight to Quality. The Review of Economics and Statistics 78(1), 1-15.

Bernanke, B. S., M. Gertler, and S. Gilchrist (1999). The Financial Accelerator in a Quantitative Business Cycle Framework. In J. Taylor and M. Woodford (Eds.), Handbook of Macroeconomics, Volume 1, pp. 1341-1393. Elsevier.

Blinder, A. S. (1987). Credit Rationing and Effective Supply Failures. The Economic Journal 97(386), 327-352.

Christiano, L. J. and M. Eichenbaum (1992). Liquidity Effects and the Monetary Transmission Mechanism. The American Economic Review 82(2), 346-353.

Christiano, L. J., M. Eichenbaum, and C. Evans (1997). Sticky Price and Limited Participation Models of Money: A Comparison. European Economic Re- 
view $41(6), 1201-1249$.

Farmer, R. E. A. (1984). A New Theory of Aggregate Supply. The American Economic Review 74 (5), 920-930.

Garcia, R. and H. Schaller (2002). Are the Effects of Monetary Policy Asymmetric? Economic Inquiry 40(1), 102-119.

Gertler, M. and S. Gilchrist (1994). Monetary Policy, Business Cycles, and the Behavior of Small Manufacturing Firms. The Quarterly Journal of Economics 109(2), 309-340.

Hansen, B. E. (1996). Inference When a Nuisance Parameter Is Not Identified Under the Null Hypothesis. Econometrica 64 (2), 413-430.

Hansen, B. E. (1997). Inference in TAR Models. Studies in Nonlinear Dynamics and Econometrics 2(1), 1-24.

Hubrich, K. and R. J. Tetlow (2012). Financial Stress and Economic Dynamics: The Transmission of Crises. The Federal Reserve Board Finance and Economics Discussion Series Working Paper No. 2012-82.

Iwata, S. and S. Wu (2006). Estimating Monetary Policy Effects when Interest Rates are Close to Zero. Journal of Monetary Economics 53(7), 1395-1408.

Kaufmann, S. (2002). Is there an asymmetric effect of monetary policy over time? A Bayesian analysis using Austrian data. Empirical Economics 27(2), 277-297.

Koop, G., M. H. Pesaran, and S. M. Potter (1996). Impulse Response Analysis in Nonlinear Multivariate Models. Journal of Econometrics 74, 119-147.

Krugman, P. R. (1998). It's Baaack: Japan's Slump and the Return of the Liquidity Trap. Brookings Papers on Economic Activity 29(2), 137-206.

McCallum, J. (1991). Credit Rationing and the Monetary Transmission Mechanism. The American Economic Review 81 (4), 946-951.

Mishkin, F. S. (2009). Is Monetary Policy Effective during Financial Crises? The American Economic Review 99(2), 573-577.

Oda, N. and K. Okina (2001). Further Monetary Easing Policies under the NonNegativity Constraints of Nominal Interest Rates: Summary of the Discussion based on Japan's Experience. Monetary and Economic Studies 19(S-1), 323-370. 
Peersman, G. and F. Smets (2002). Are the Effects of Monetary Policy in the Euro Area Greater in Recessions than in Booms? In L. Mahadeva and P. Sinclair (Eds.), Monetary Transmission in Diverse Economies, pp. 28-48. Cambridge University Press, Cambridge, UK.

Ravn, S. H. (2012). Asymmetric Monetary Policy Towards the Stock Market: A DSGE Approach. Danmarks National Bank Working Papers No. 77.

Weise, C. L. (1999). The Asymmetric Effects of Monetary Policy: A Nonlinear Vector Autoregression Approach. Journal of Money, Credit and Banking 31(1), 85-108.

\section{Appendix A: Data sources}

Table A1: Data sources used in this paper

\begin{tabular}{llll}
\hline Variable & Data used & Source & $\begin{array}{l}\text { Mnemonic } \\
\text { code }\end{array}$ \\
\hline Real GDP & $\begin{array}{l}\text { Real Gross Domestic } \\
\text { Product, 3 Decimal }\end{array}$ & FRED & GDPC96 \\
\hline Inflation & $\begin{array}{l}\text { Consumer Price Index } \\
\text { for All Urban Consumers: } \\
\text { All Items }\end{array}$ & FRED & CPIAUCSL \\
\hline $\begin{array}{llll}\text { Commodity price } \\
\text { index }\end{array}$ & $\begin{array}{l}\text { Continuous Commodity } \\
\text { Index }\end{array}$ & Bloomberg & CCI:IND \\
\hline Federal funds rate & Effective Federal Funds Rate & FRED & FEDFUNDS \\
\hline $\begin{array}{l}\text { Financial conditions } \\
\text { index }\end{array}$ & $\begin{array}{l}\text { Adjusted National } \\
\text { Financial Conditions Index }\end{array}$ & $\begin{array}{l}\text { Chicago Federal } \\
\text { Reserve }\end{array}$ & ANFCI \\
\hline Exchange rate & $\begin{array}{l}\text { Real Trade Weighted } \\
\text { U.S. Dollar Index: } \\
\text { Major Currencies }\end{array}$ & FRED & TWEXMPA \\
\hline
\end{tabular}




\section{Appendix B: Algorithm for computation of nonlinear impulse responses}

The computation of nonlinear impulse response functions (IRFs) follows Koop, Pesaran, and Potter (1996). A nonlinear impulse response function is defined as the impact of a one-time shock on the variables, $Y_{t}$, in the model, conditioned on the history and/or the shock. The nonlinear IRF can be expressed as:

$$
\operatorname{IRF}\left(n, u_{t}, \psi_{t-1}\right)=E\left[y_{t+n} \mid \psi_{t-1}, u_{t}\right]-E\left[y_{t+n} \mid \psi_{t-1}\right] .
$$

The response of a variable $y$ at horizon $n$ can then be calculated as the differences in two conditional expectations. First, the evolution of the VAR system conditional on a certain history $\psi_{t-1}$ following the shock $u_{t}$ is simulated. Second, the evolution of the VAR system conditional on the same history, $\psi_{t-1}$, without imposing the shock $u_{t}$ at time $t$ is simulated and subtracted from the former computed conditional expectation. To obtain the impulse responses of the VAR system conditional on the regimes (above or below the threshold value), the simulations are repeated for a sufficient number of histories which correspond to the respective regime. Random shocks are allowed to hit the VAR system before and after the shock. The nonlinear IRF approach relies on the simulation of the VAR system under multiple sequences of the shocks. Taking an average of the conditional means of the generated nonlinear IRFs evens out the shocks that were used to generate the simulations. The result is the response of the system with history $\psi_{t-1}$ conditional on the shock $u_{t}$ only.

The following algorithm is used to compute the nonlinear IRFs.

1. Pick a history, $\psi_{t-1}^{r}$, from the regime that is chosen. This history comprises the actual value of all the lagged endogenous variables in the VAR at the chosen date. This implies that the realization of the threshold variable, $t_{t-1}^{r}$, is also randomly drawn from the selected regime.

2. The shocks are drawn from the variance-covariance matrix of the residuals and assume to be jointly distributed. A $k$-dimensional vector $u_{t+n}^{b}, n=0, \ldots, p$ is drawn at each horizon, where $k$ denotes the number of endogenous variables in the VAR. Hence, if a shock is drawn at horizon $p$, all $\mathrm{k}$ residuals for date $p$ are collected. 
3. The evolution of all variables in the VAR system over $n+1$ periods is simulated using the coefficients that are estimated for both the low and high financial stress regimes and the shock process for $n+1$ periods. This implies that the model is allowed to switch regimes over the forecast horizon. The resulting baseline path is denoted as $Y_{t+n}\left(t_{t-1}^{r}, u_{t+n}^{b}\right)$.

4. Step 4 is essentially the same as step 3 , with the shock sequence at $t=0$ replaced by a shock of size $\eta_{j}$ for the variable $j$ and the contemporaneous shocks of other variables in the system. This $k \times 1$ vector is denoted as $u_{j}^{*}$. The resulting path is denoted as $Y_{t+n}\left(t_{t-1}^{r}, u_{t+n}^{b}, u_{j}^{*}\right)$.

5. Steps 2 to 4 are repeated $\mathrm{R}$ times to allow the shocks to average out. In this paper, $\mathrm{R}$ is set to 500 times.

6. Steps 1 to 5 are repeated B times to compute an average over the history of each regime, and to even out the $\mathrm{R}$ times of shock sequences. In this paper, $\mathrm{B}$ is set to 500 times.

7. The nonlinear IRF is then the difference between the two simulated forecasts assuming the shock $u_{j}^{*}$ and assuming zero respectively.

$$
\operatorname{IRF}\left(n, \psi_{t-1}, u_{j}^{*}\right)=\left[Y_{t+n}\left(t_{t-1}^{r}, u_{t+n}^{b}, u_{j}^{*}\right)-Y_{t+n}\left(t_{t-1}^{r}, u_{t+n}^{b}\right)\right] /(B \times R) .
$$

\section{Appendix C: Confidence bands for nonlinear impulse responses}

The simulation of nonlinear IRFs is computationally intensive, taking several hours if $\mathrm{R}$ and $\mathrm{B}$ are set to 1000 simulations runs, even when using parallel computing to reduce computation time. If the number of bootstrap replications for the confidence bands are set to 1000 simulation runs, the entire process would be equivalent to a simulation of $10^{9}$ repetitions. In this paper, $\mathrm{R}$ and $\mathrm{B}$ are reduced to 500 simulation runs, and the number of bootstrap repetitions is set to 500, for efficiency purposes. This allows the simulation of the bootstrapped confidence bands to be completed in approximately one week. The following algorithm is used to compute the bootstrapped confidence intervals. 
1. Compute centered residuals, $\hat{u}-\bar{u}$, and generate bootstrap residuals, $u^{*}$, by drawing randomly with replacement from centered residuals.

2. Using the estimated parameters and errors from the TVAR structure, data is generated recursively.

3. Using the recursive dataset, the regression coefficients $B_{1}, \gamma_{1}(L), B_{2}, \gamma_{2}(L)$ and error terms are calculated from the TVAR with the assumption that threshold is equivalent to the estimated value $\phi$.

4. Using the original dataset, but with the coefficients and errors from step 2, nonlinear IRFs are calculated using the algorithm listed in the previous section for all combination of shocks and initial conditions.

5. Steps 1 to 3 are repeated $\mathrm{Z}$ times, set to 500 bootstrap repetitions in this paper, to generate a sampling distribution of the IRFs. The confidence bands are then drawn from the ordered bootstrap estimates at the respective significance levels.

\section{Appendix D: Confidence bands for the impulse re- sponses estimated from sample 1973Q1 - 2008Q4}

This section provides the confidence bands for the regime-dependent and nonlinear impulse responses.

\section{Appendix E: Impulse responses for 1973Q1 - 2012Q4 sample}




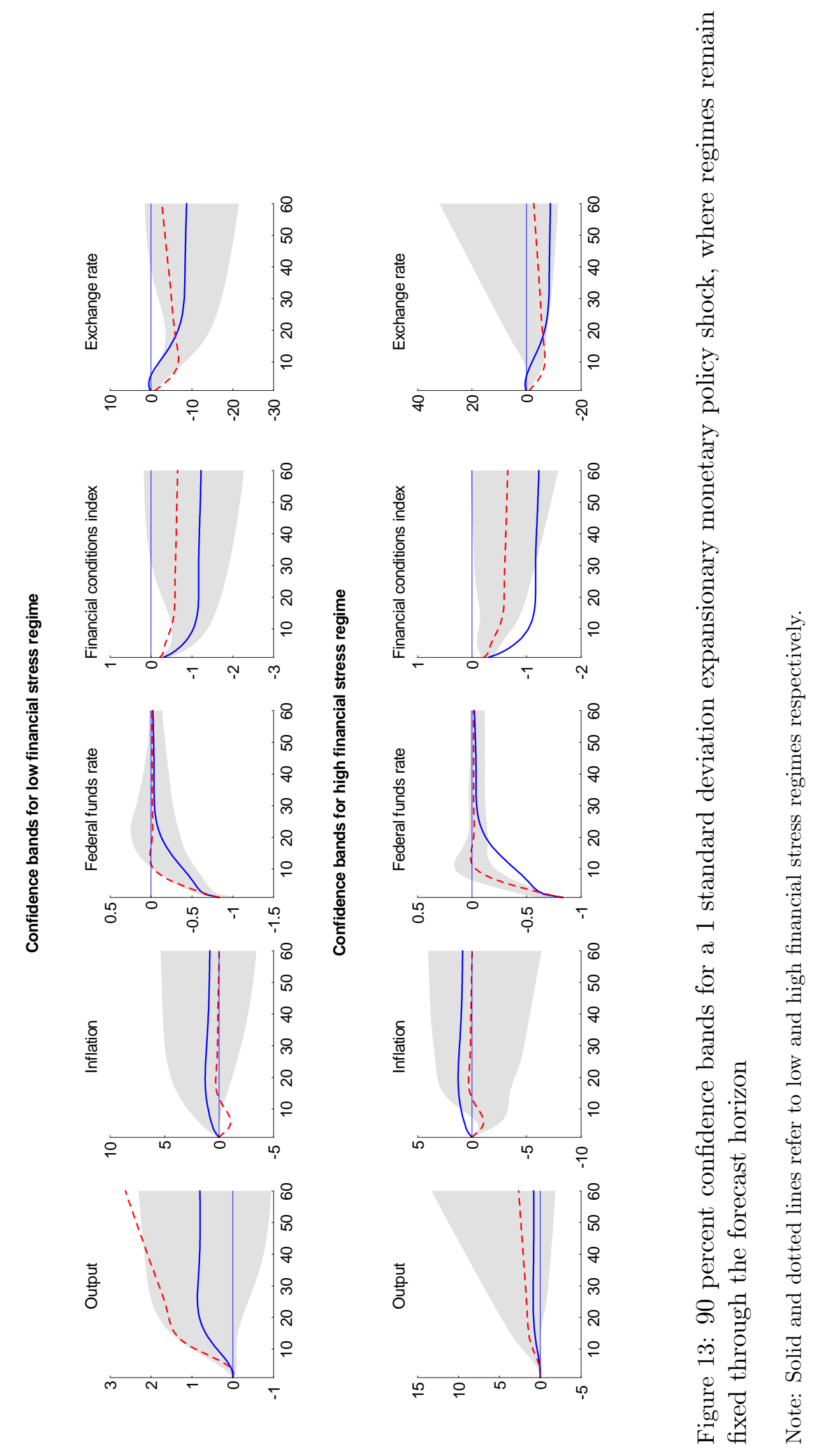




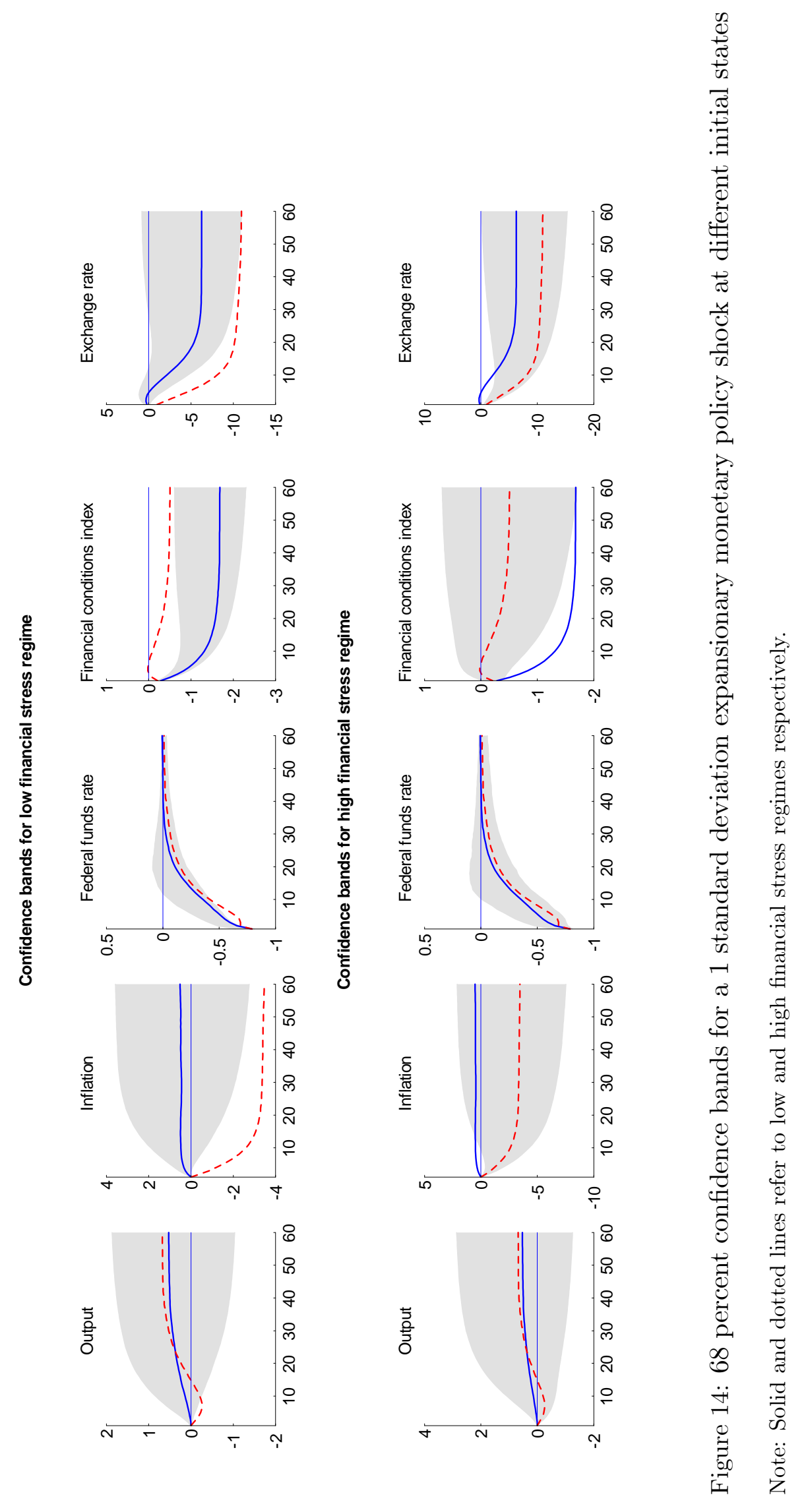




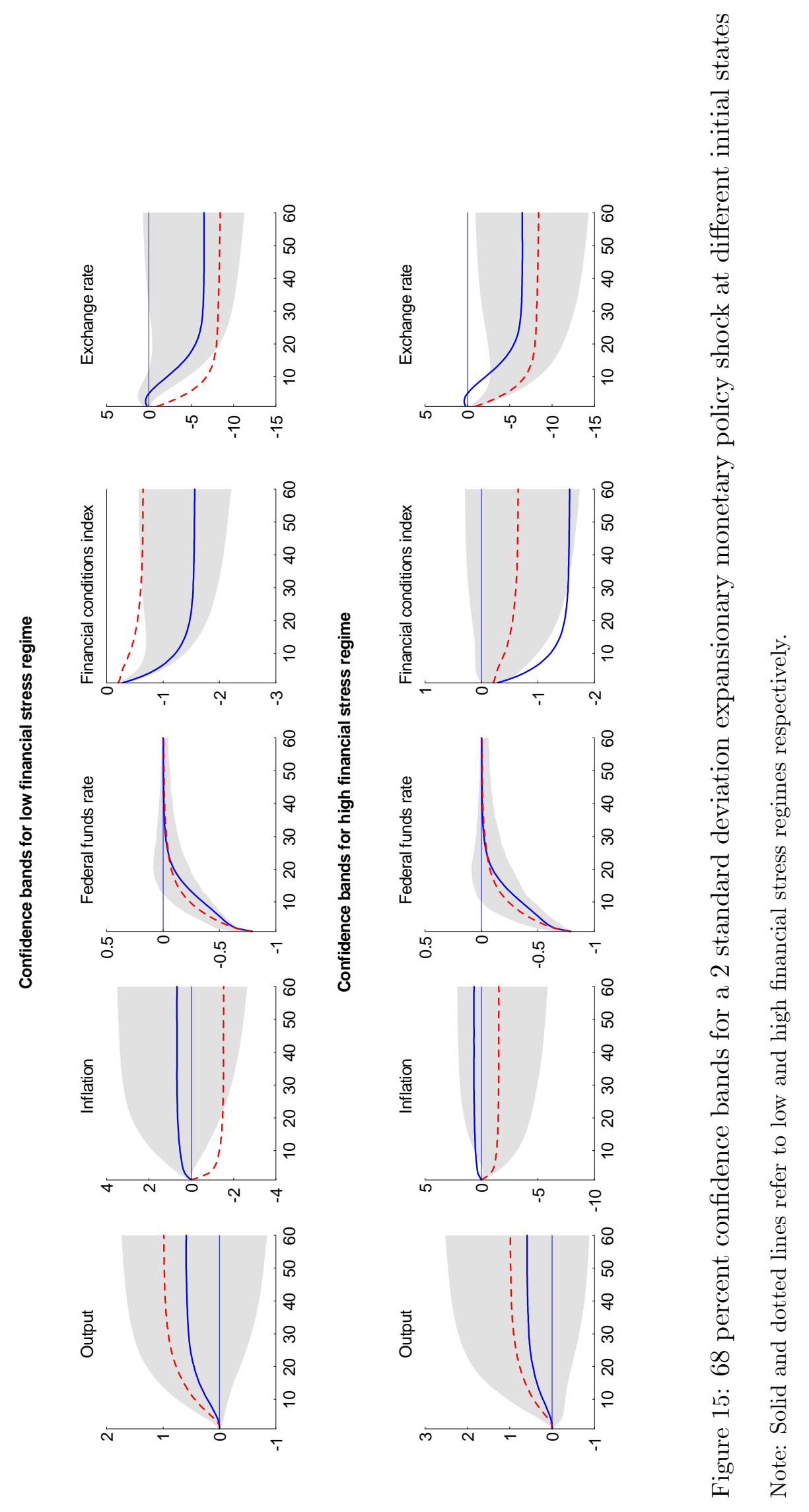



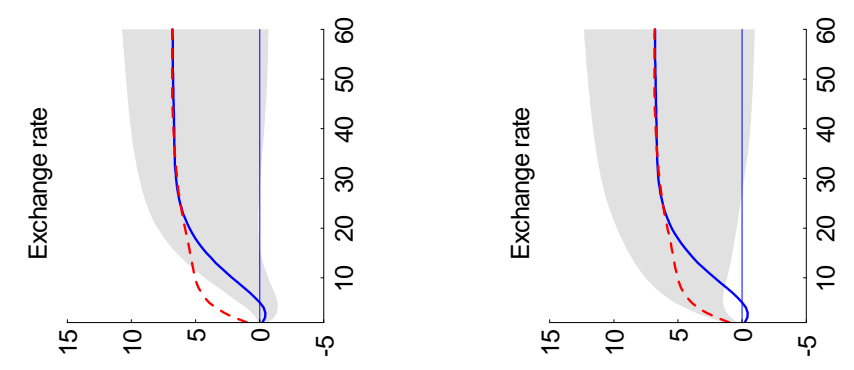

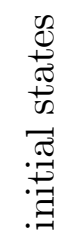

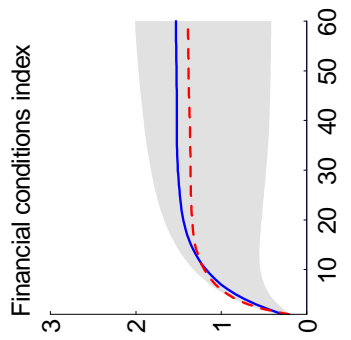

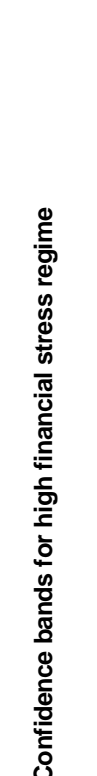
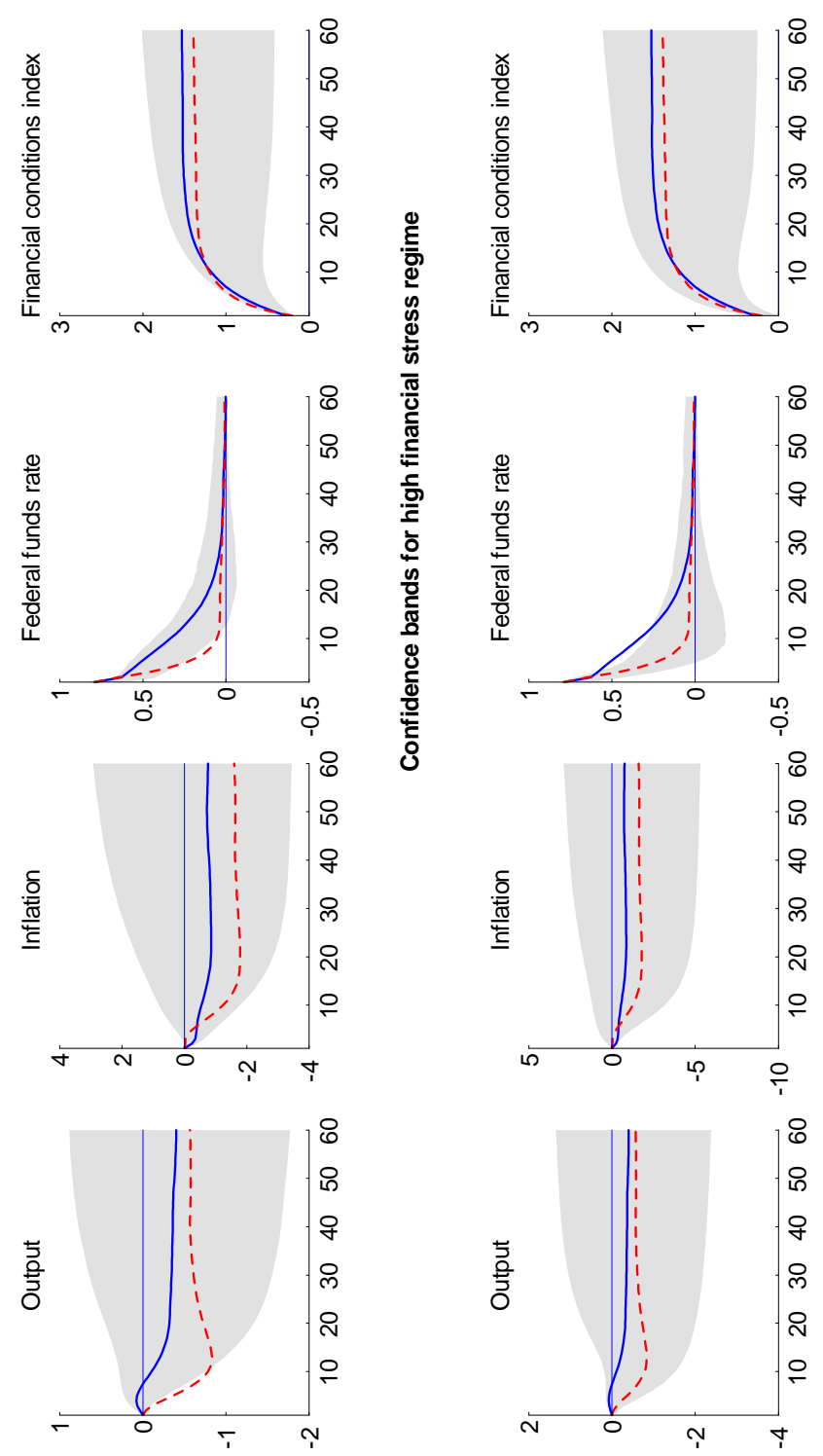

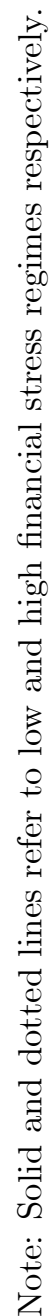

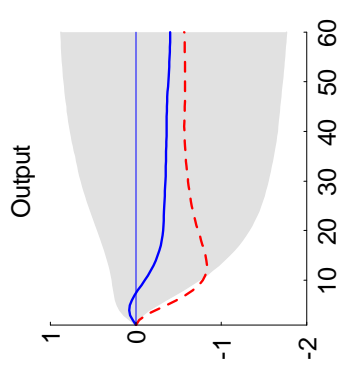

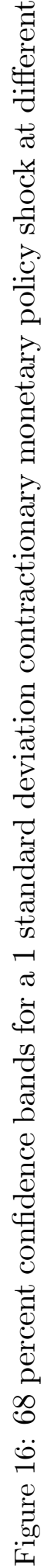

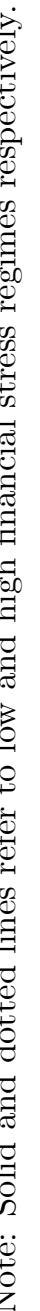



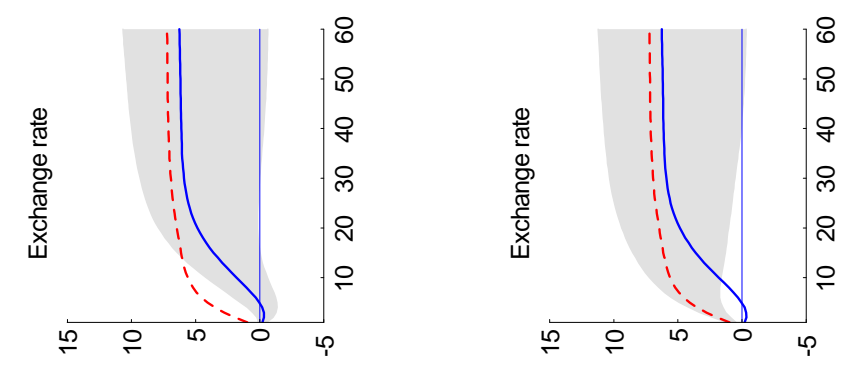

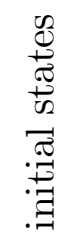
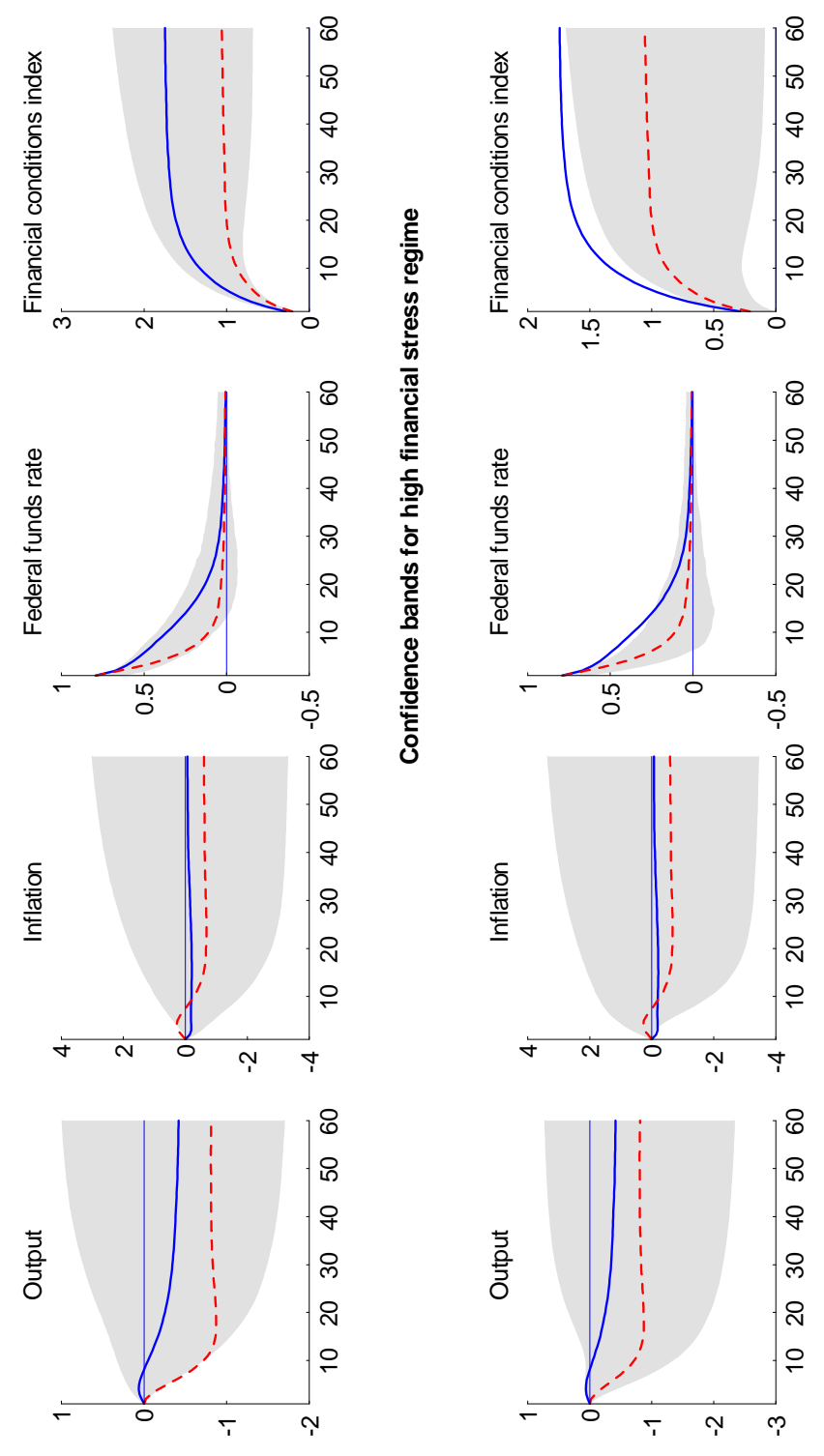

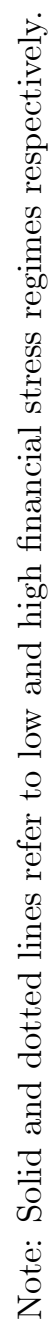
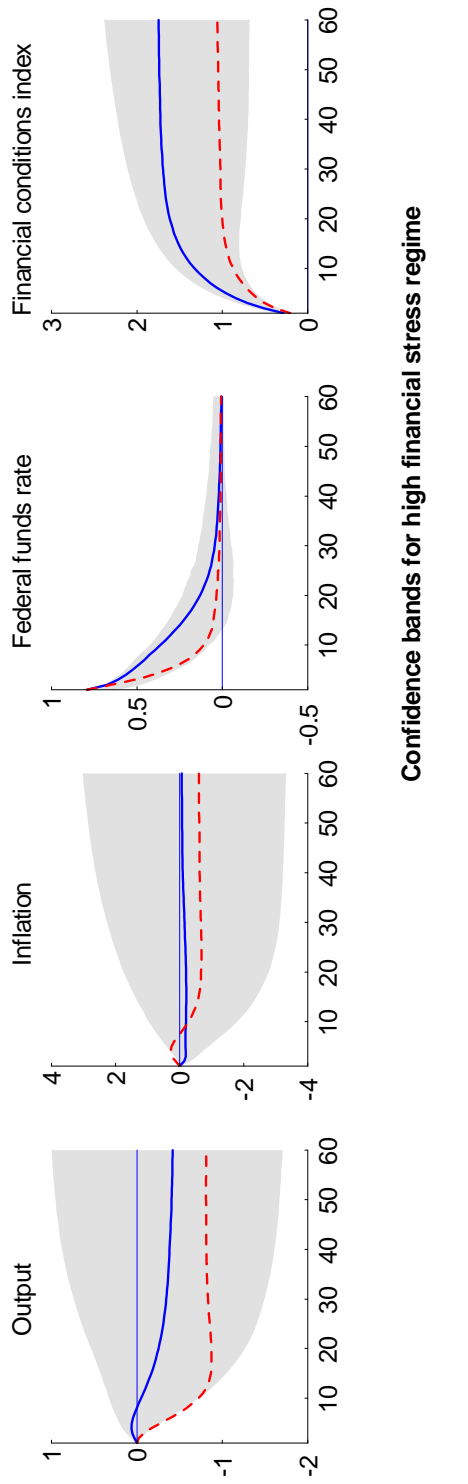

0
0
0
0
0
0
0
0
0
0
0
07
0
0
0
0

:

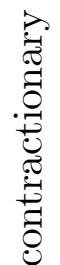

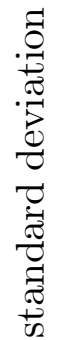




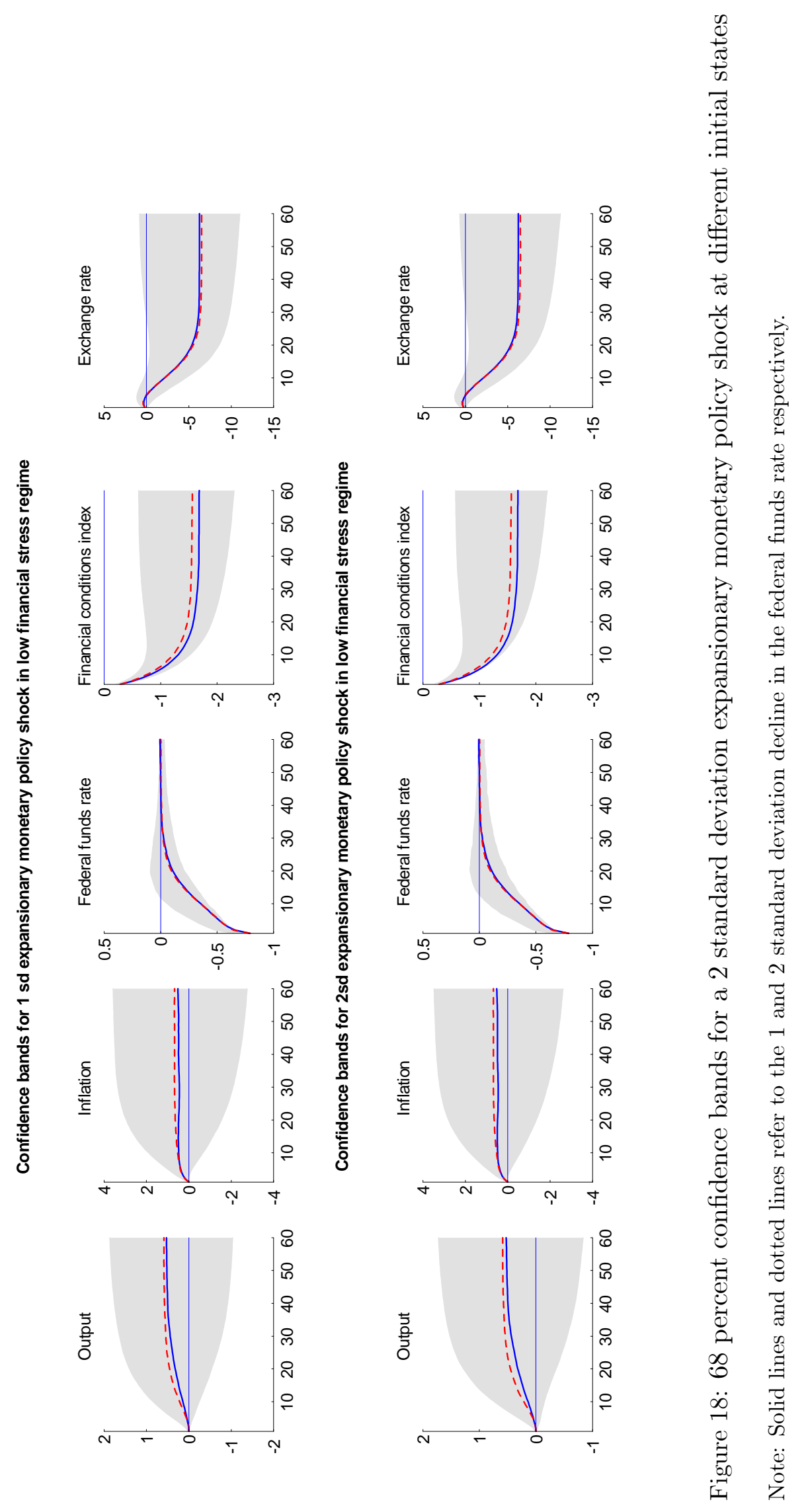



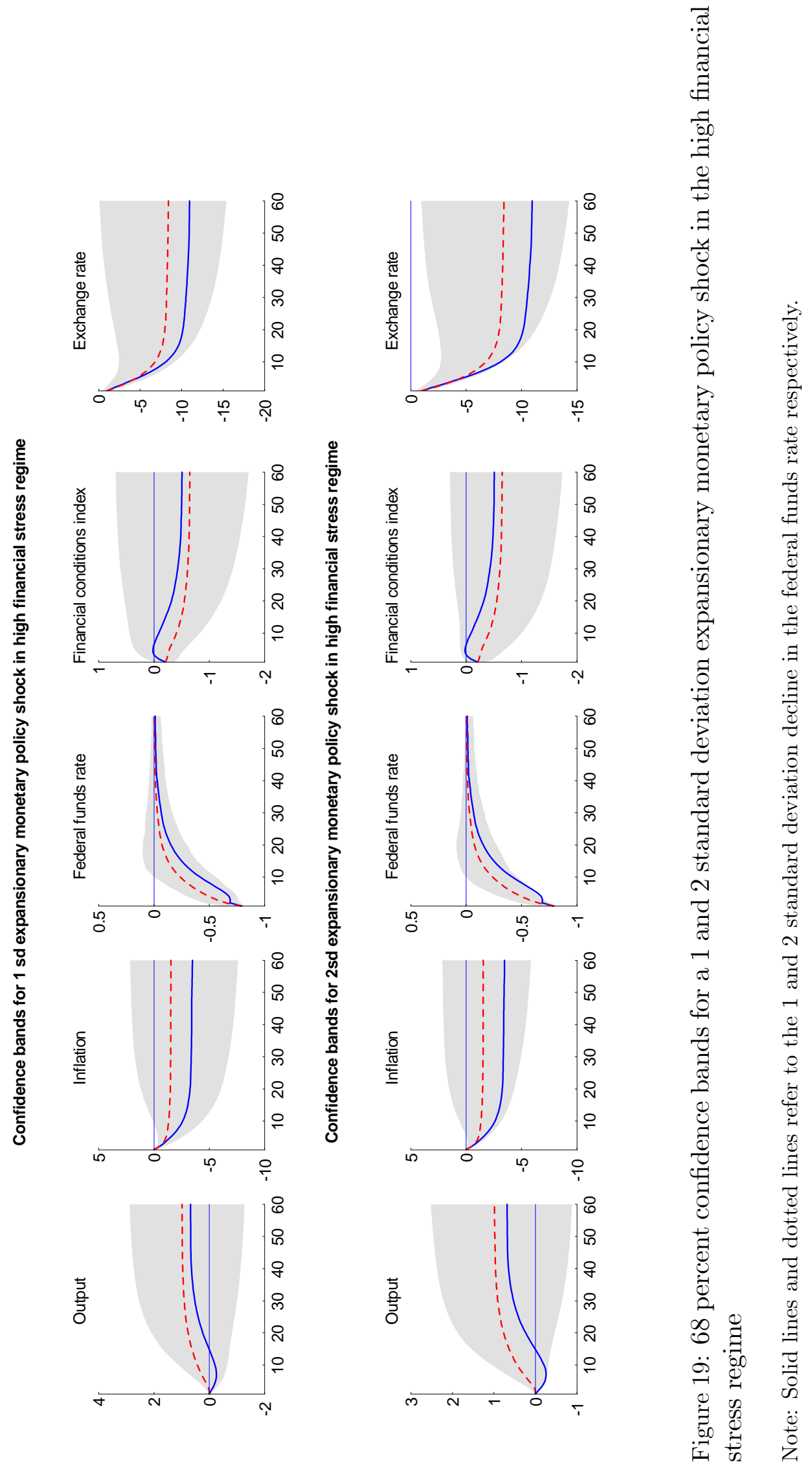


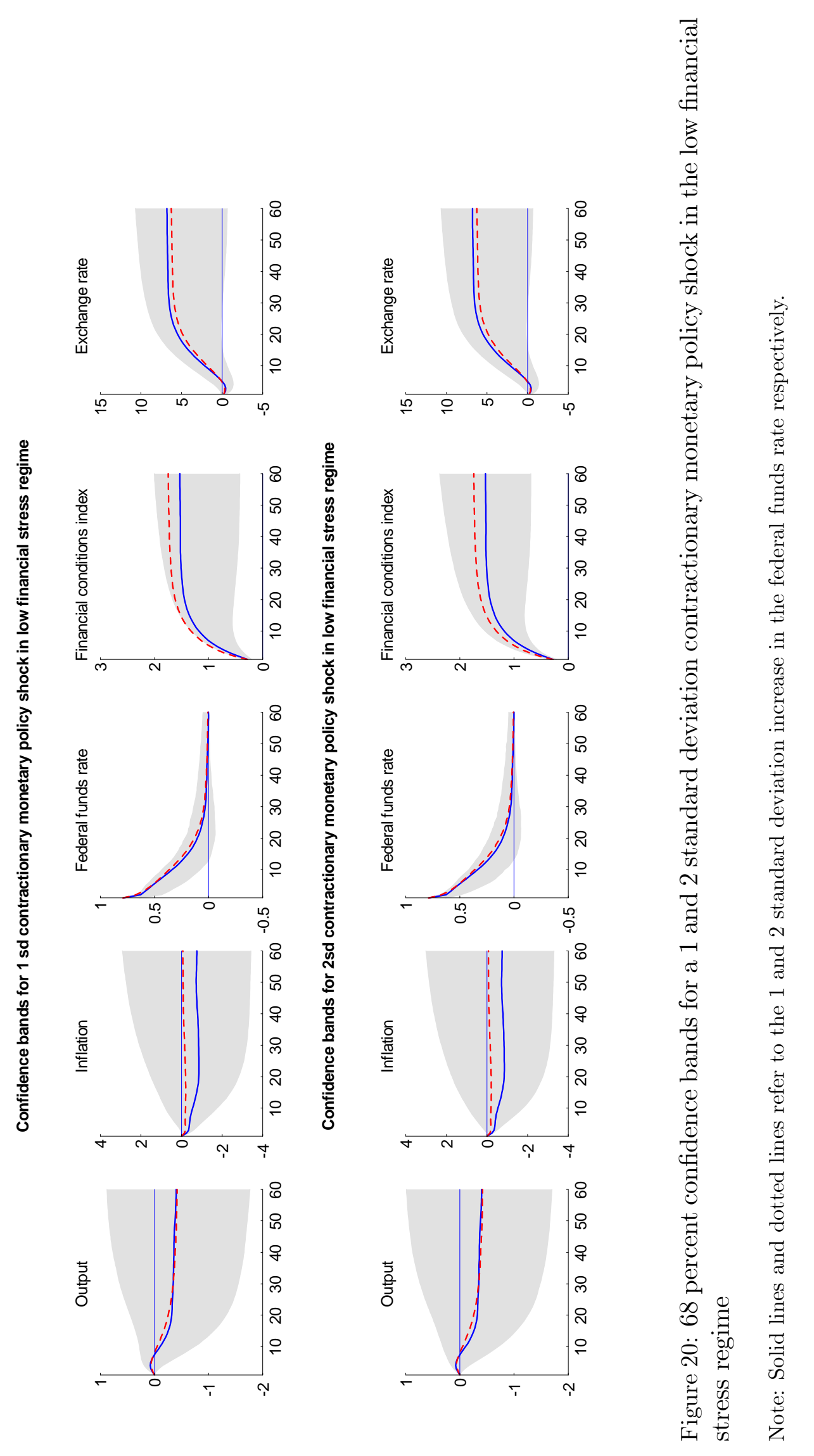




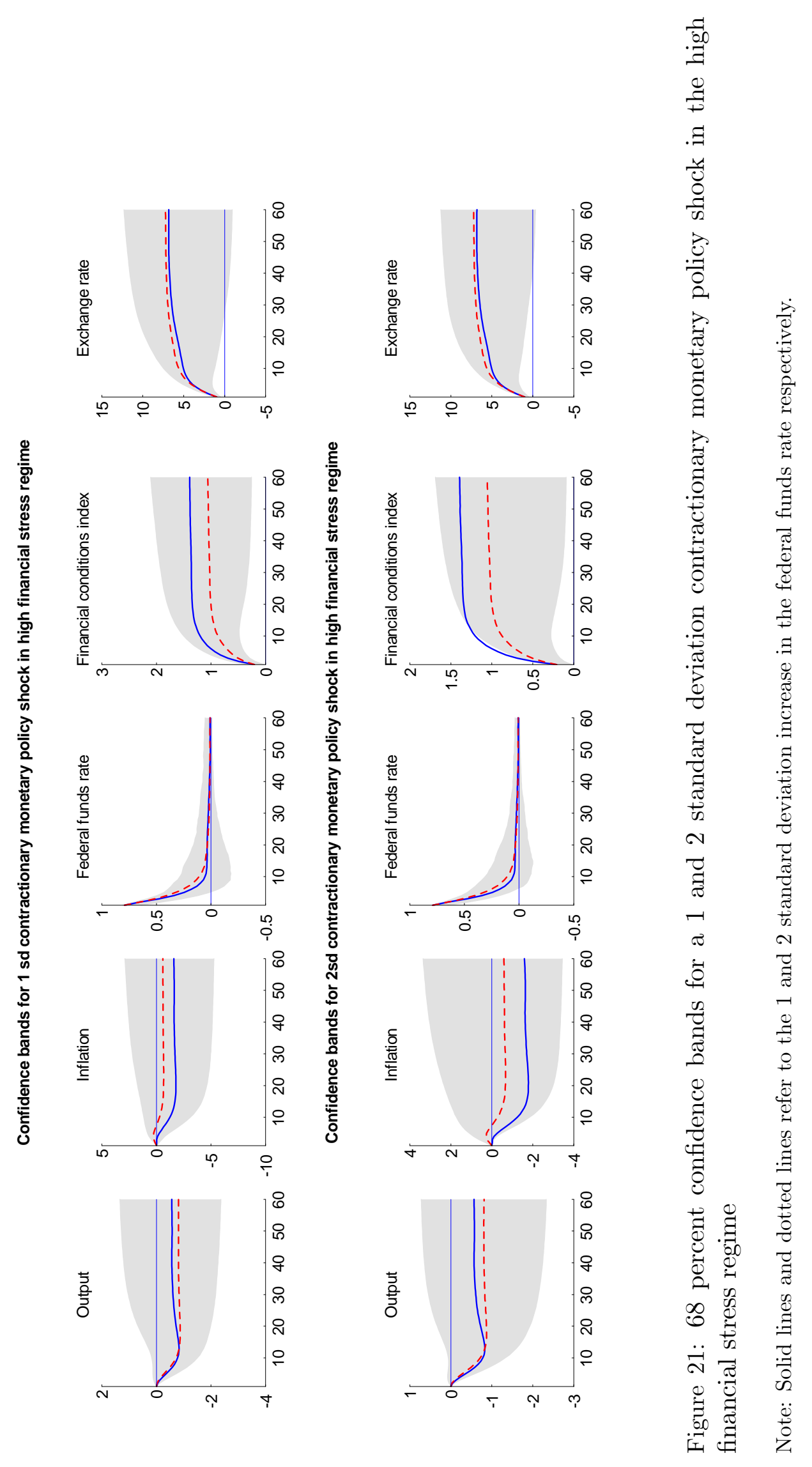



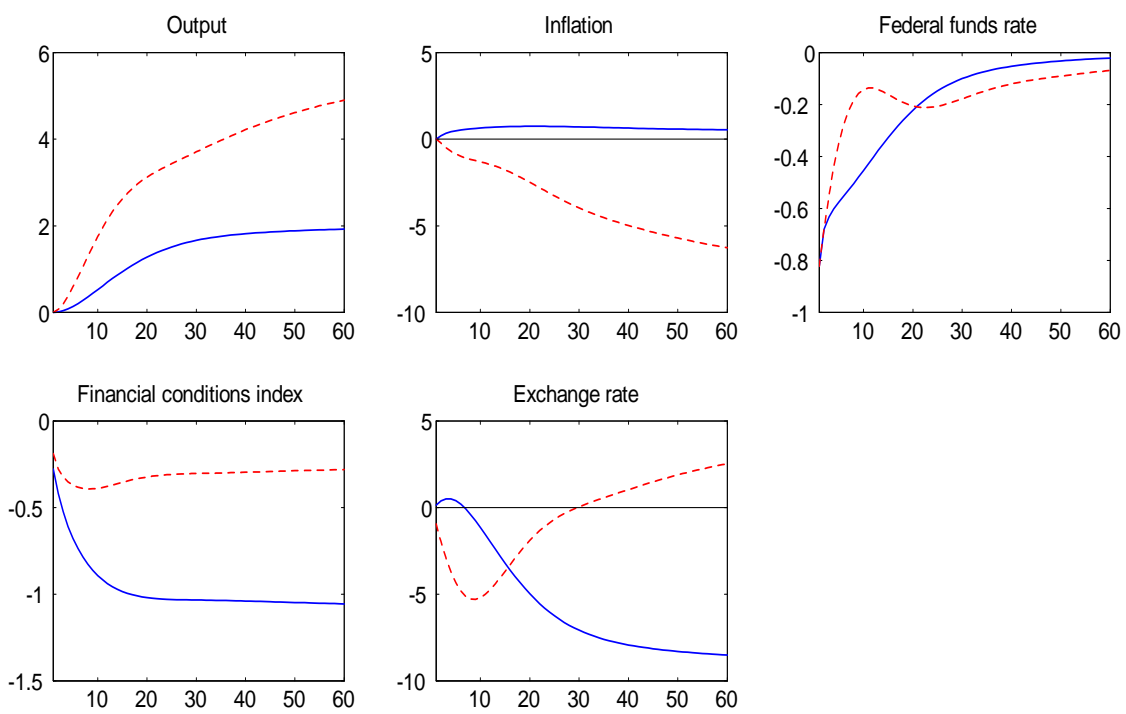

Figure 22: Impact of a 1 standard deviation decline in the federal funds rate in the low financial stress and high financial stress regimes.

Note: Solid lines and dotted lines refer to the low and high financial stress regimes respectively.
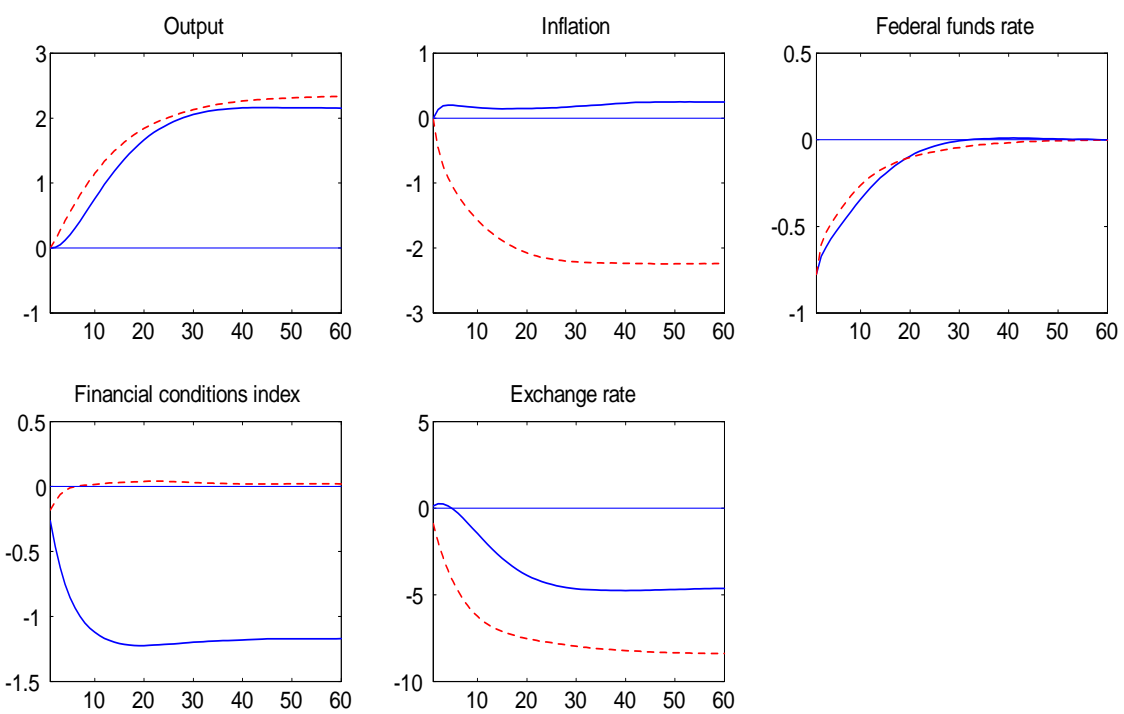

Figure 23: Impact of a 1 standard deviation expansionary monetary policy shock at different initial states.

Note: Solid lines and dotted lines refer to the low and high financial stress regimes respectively. 

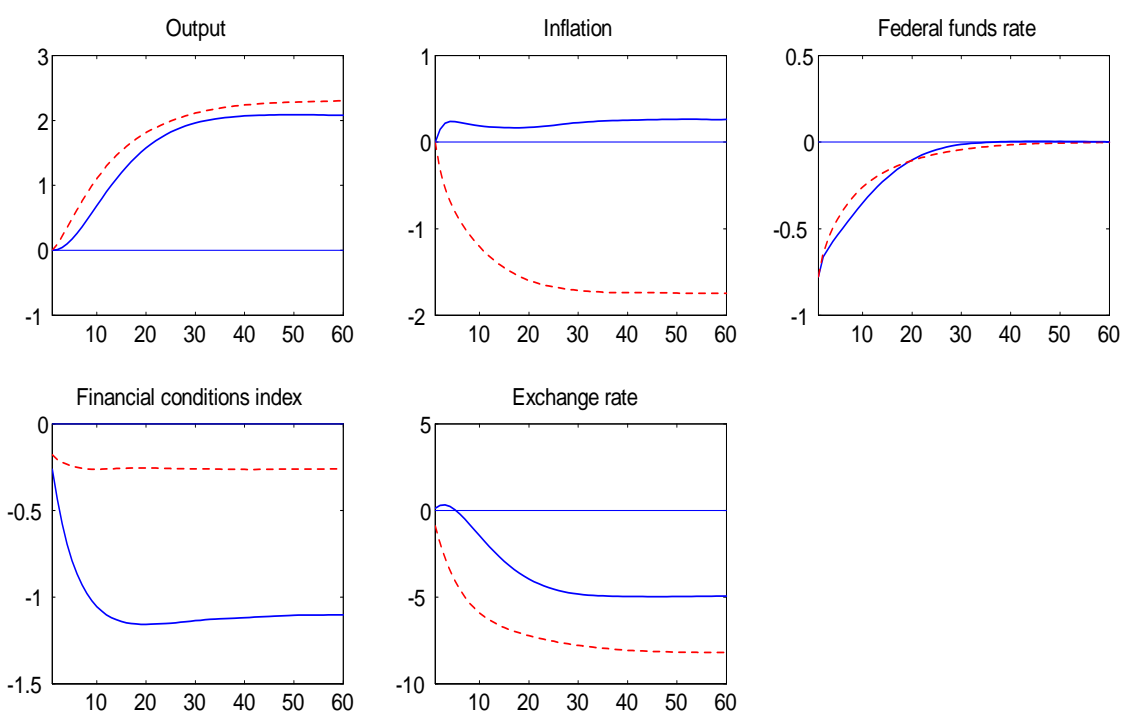

Figure 24: Impact of a 2 standard deviation expansionary monetary policy shock at different initial states.

Note: Solid lines and dotted lines refer to the low and high financial stress regimes respectively.
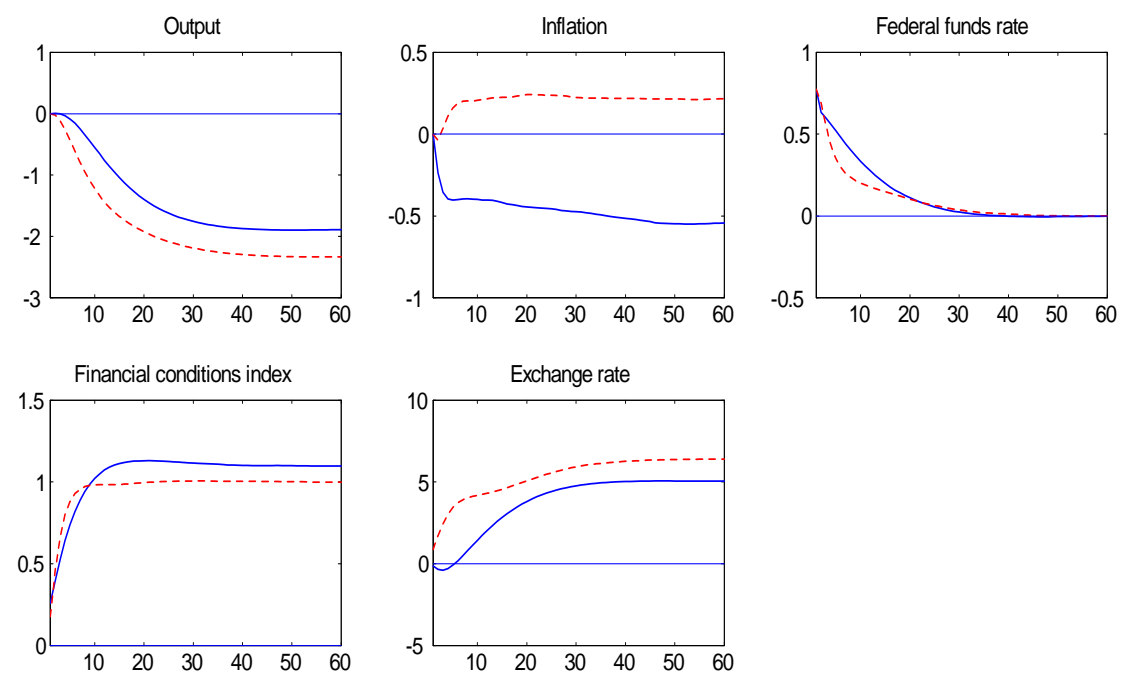

Figure 25: Impact of a 1 standard deviation contractionary monetary policy shock at different initial states.

Note: Solid lines and dotted lines refer to the low and high financial stress regimes respectively. 

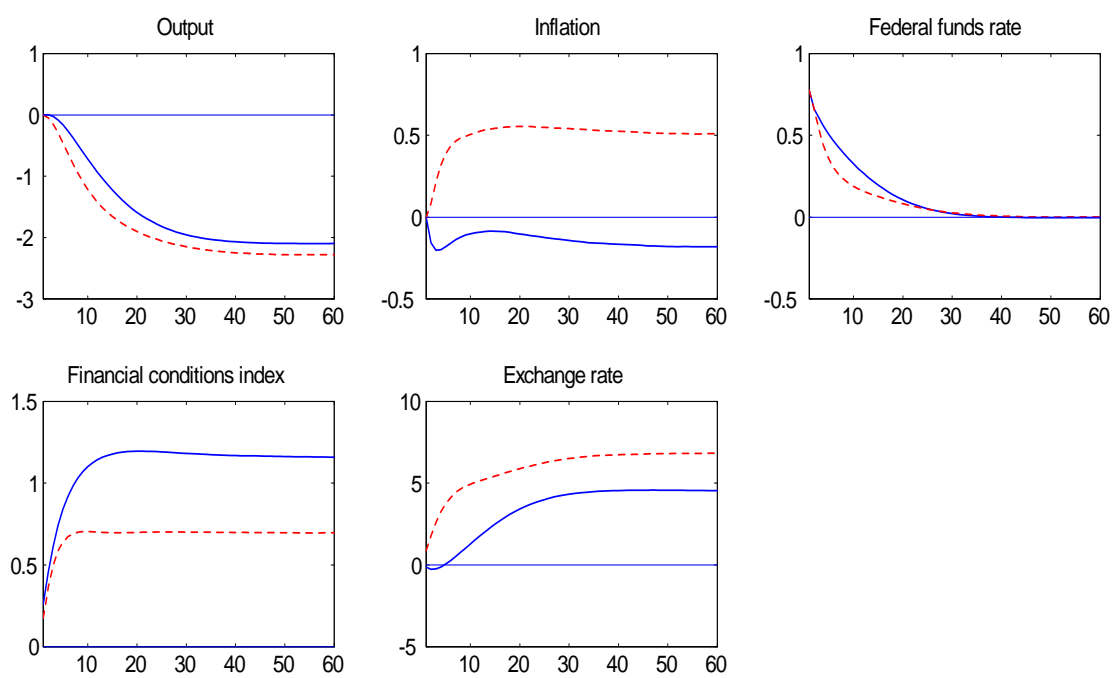

Figure 26: Impact of a 2 standard deviation contractionary monetary policy shock at different initial states.

Note: Solid lines and dotted lines refer to the low and high financial stress regimes respectively.
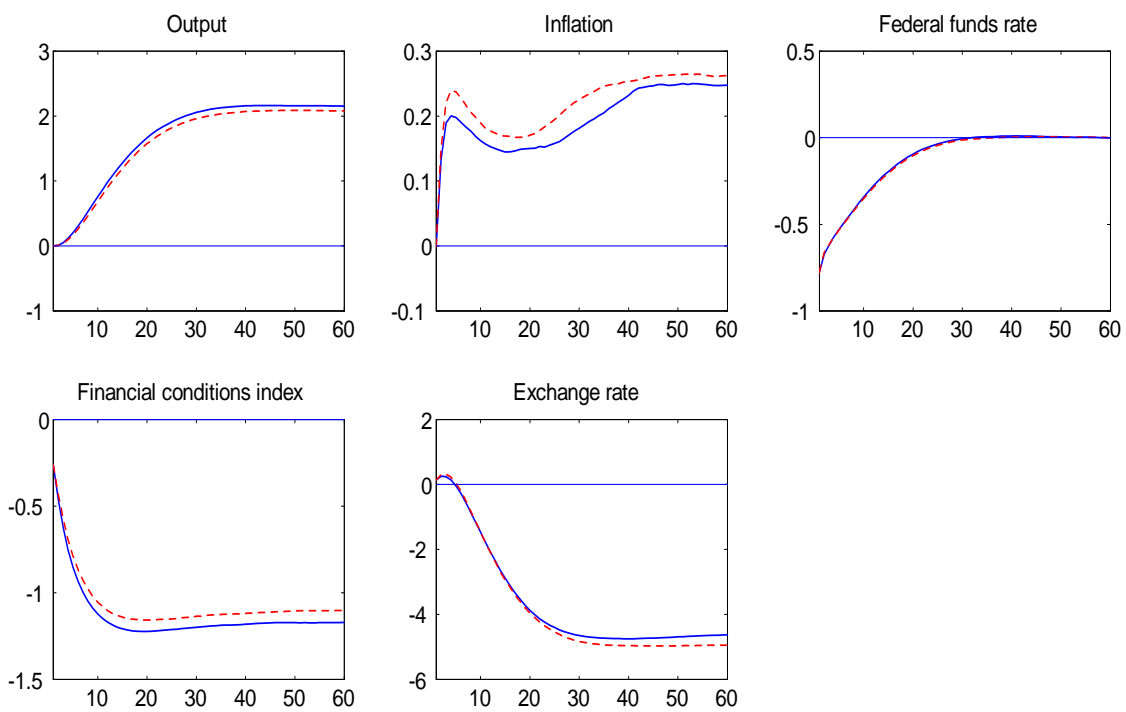

Figure 27: Impact of a 1 and 2 standard deviation expansionary monetary policy shock in the low financial stress regime.

Note: Solid lines and dotted lines refer to the 1 and 2 standard deviation decline in the federal funds rate respectively. 

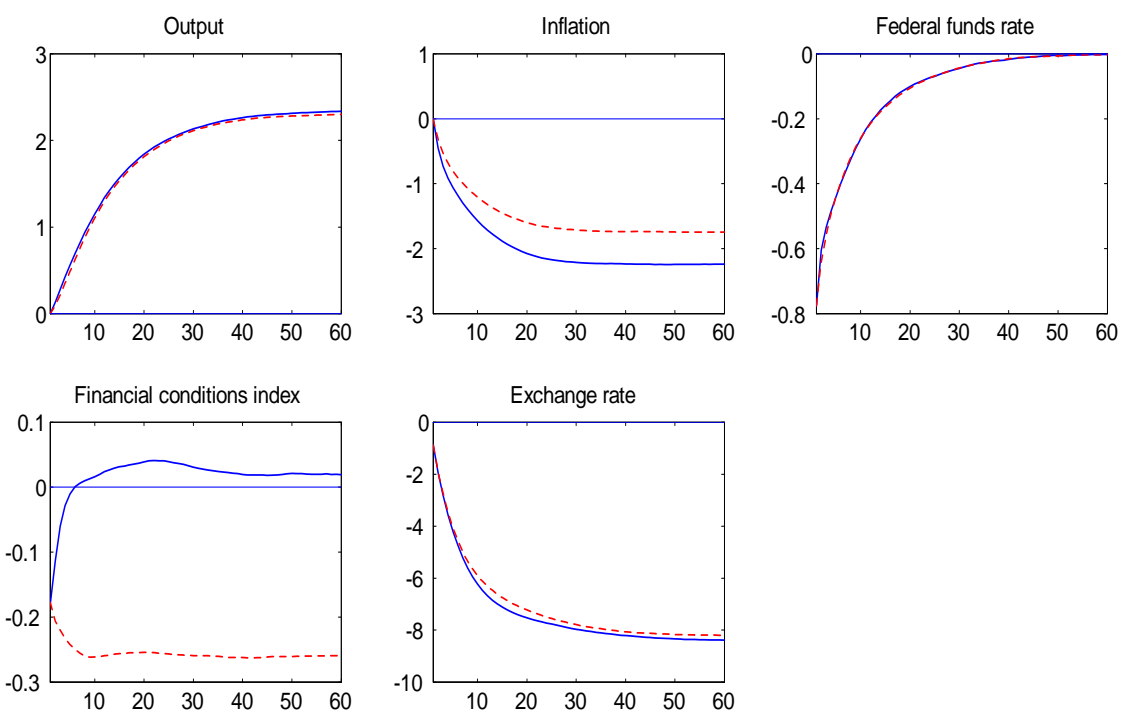

Figure 28: Impact of a 1 and 2 standard deviation expansionary monetary policy shock in the high financial stress regime.

Note: Solid lines and dotted lines refer to the 1 and 2 standard deviation decline in the federal funds rate respectively.
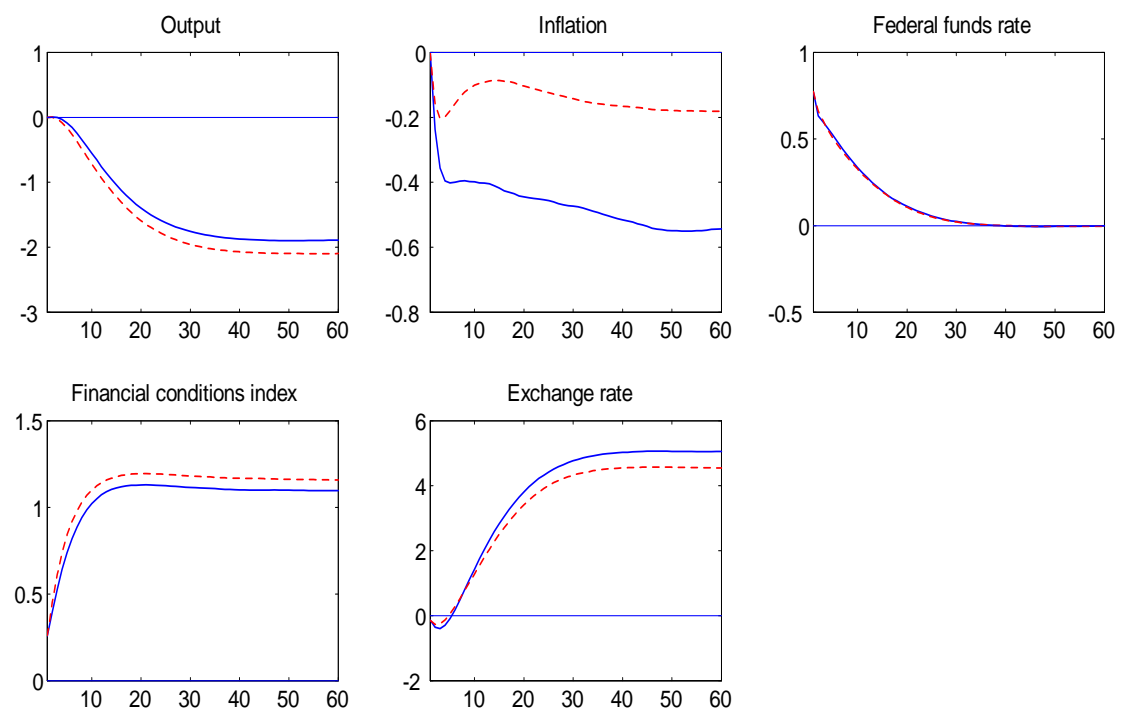

Figure 29: Impact of a 1 and 2 standard deviation contractionary monetary policy shock in the low financial stress regime.

Note: Solid lines and dotted lines refer to the 1 and 2 standard deviation increase in the federal funds rate respectively. 

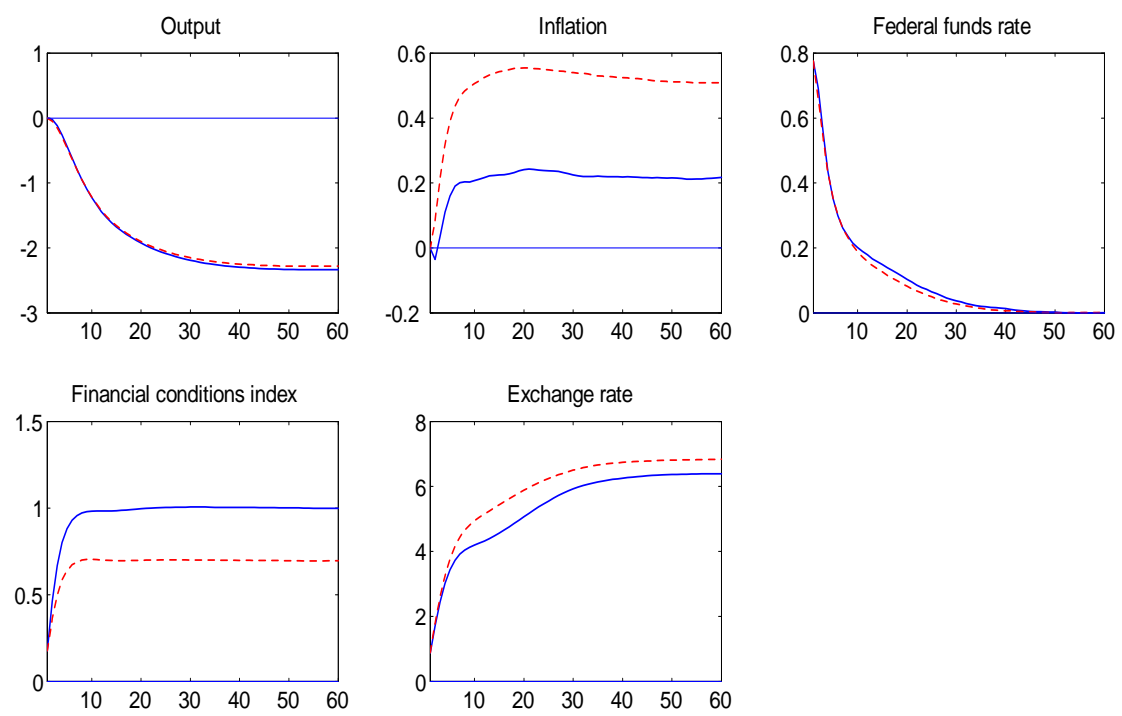

Figure 30: Impact of a 1 and 2 standard deviation contractionary monetary policy shock in the high financial stress regime.

Note: Solid lines and dotted lines refer to the 1 and 2 standard deviation increase in the federal funds rate respectively. 